\title{
Evaluation of near-tropopause ozone distributions in the Global Modeling Initiative combined stratosphere/troposphere model with ozonesonde data
}

\author{
D. B. Considine ${ }^{1}$, J. A. Logan $^{2}$, and M. A. Olsen ${ }^{3}$ \\ ${ }^{1}$ NASA Langley Research Center, Hampton, Virginia, USA \\ ${ }^{2}$ Harvard University, Cambridge, Massachusetts, USA \\ ${ }^{3}$ Goddard Earth Sciences and Technology Center, University of Maryland, Baltimore County, Baltimore, Maryland, USA
}

Received: 19 November 2007 - Published in Atmos. Chem. Phys. Discuss.: 29 January 2008

Revised: 15 April 2008 - Accepted: 18 April 2008 - Published: 6 May 2008

\begin{abstract}
The NASA Global Modeling Initiative has developed a combined stratosphere/troposphere chemistry and transport model which fully represents the processes governing atmospheric composition near the tropopause. We evaluate model ozone distributions near the tropopause, using two high vertical resolution monthly mean ozone profile climatologies constructed with ozonesonde data, one by averaging on pressure levels and the other relative to the thermal tropopause. At the tropopause, model ozone is high-biased in the SH tropics and $\mathrm{NH}$ midlatitudes by $\sim 45 \%$ in a $4^{\circ}$ latitude $\times 5^{\circ}$ longitude model simulation. Doubling the resolution to $2^{\circ} \times 2.5^{\circ}$ increases the $\mathrm{NH}$ high bias to $\sim 60 \%$, and reduces the tropical bias to $\sim 30 \%$, apparently due to decreased horizontal transport between the tropics and extratropics in the higher-resolution simulation. These ozone biases do not appear to be due to an overly vigorous residual circulation, insufficient convection, or excessive stratosphere/troposphere exchange, and so may be due to insufficient vertical resolution or excessive vertical diffusion near the tropopause. In the upper troposphere and lower stratosphere, model/measurement intercomparisons are strongly affected by the averaging technique.

Compared to the pressure-averaged climatology, $\mathrm{NH}$ and tropical mean model lower stratospheric biases are $<20 \%$. In the upper troposphere, the $2^{\circ} \times 2.5^{\circ}$ simulation shows mean high biases of $\sim 20 \%$ and $\sim 35 \%$ during April in the tropics and NH midlatitudes, respectively. This apparently good
\end{abstract}

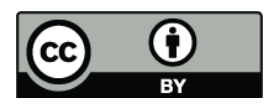

Correspondence to: D. Considine (david.b.considine@nasa.gov) model/measurement agreement degrades when relative-totropopause averages are considered, with upper troposphere high biases of $\sim 30 \%$ and $70 \%$ in the tropics and $\mathrm{NH}$ midlatitudes. This occurs because relative-to-tropopause averaging better preserves the larger cross-tropopause $\mathrm{O}_{3}$ gradients which are seen in the daily sonde data, but not in daily model profiles. Relative-to-tropopause averages therefore more accurately reveal model/measurement discrepancies. The relative annual cycle of ozone near the tropopause is reproduced very well in the model Northern Hemisphere midlatitudes. In the tropics, the model amplitude of the near-tropopause annual cycle is weak. This is likely due to the annual amplitude of mean vertical upwelling near the tropopause, which analysis suggests is $\sim 30 \%$ weaker than in the real atmosphere.

\section{Introduction}

The tropopause is surrounded by a transition region that is strongly influenced by both tropospheric and stratospheric processes (Holton et al., 1995; Wennberg, et al., 1998; Rood et al., 2000; Gettelman et al., 2004; Pan et al., 2004). It is a challenge to represent this "near-tropopause region" (NTR) in global models of atmospheric composition. Many models do not consider all of the processes that influence the NTR, because they were designed for reasons of practicality and interest to focus on either the stratosphere or the troposphere, but not both (e.g., Douglass and Kawa, 1999; Bey et al., 2001; Horowitz et al., 2003; Rotman et al., 2001).

Computational advances have allowed a class of composition models to be developed recently that include both the

Published by Copernicus Publications on behalf of the European Geosciences Union. 


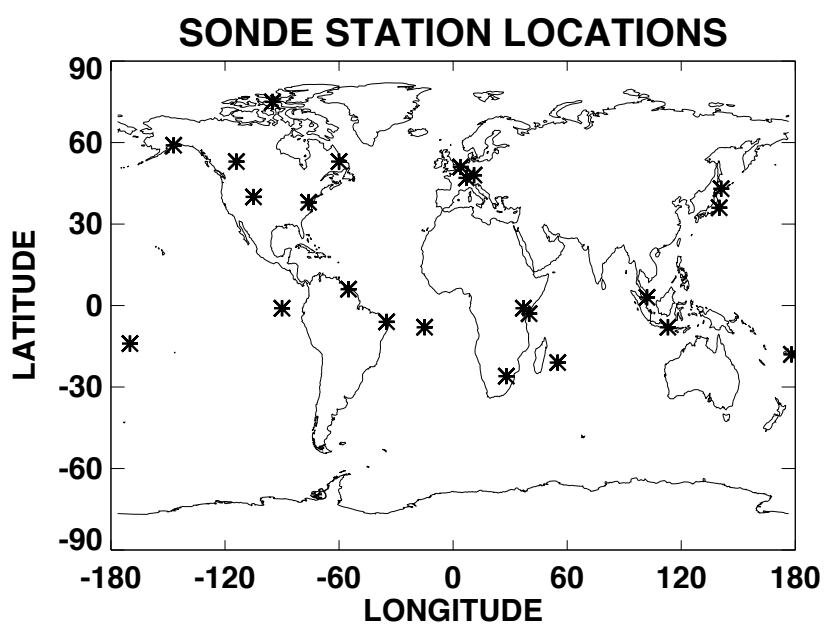

Fig. 1. Geographic locations of the 23 ozonesonde stations used in this study. Station names, latitudes and longitudes, and record length are given in Table 1.

stratosphere and the troposphere (e.g., Rotman et al., 2004; Chipperfield, 2006; Kinnison et al., 2007). The NASA Global Modeling Initiative (GMI) has constructed such a model (the Combo model), which includes a nearly complete treatment of both stratospheric and tropospheric photochemical and physical processes (Schoeberl et al., 2006; Ziemke et al., 2006; Duncan et al., 2007; Strahan et al., 2007). It uses the Lin and Rood (1996) transport scheme, which has been shown recently to be superior to spectral and semiLagrangian transport in representing the strong vertical tracer gradients that characterize the NTR (Rasch et al., 2006).

The Combo model has been shown to have many favorable characteristics in the NTR, when it utilizes meteorological data from a GCM. This includes good lower stratospheric transport (Douglass et al., 2003), and credible cross-tropopause mass and ozone fluxes (Olsen et al., 2004). Schoeberl et al. (2006) demonstrated that the Combo model reproduces the observed "tape recorder" characteristics of CO across the tropical tropopause. Strahan et al. (2007) showed that the model agrees well with many characteristics of satellite and aircraft observations of $\mathrm{CO}, \mathrm{O}_{3}, \mathrm{~N}_{2} \mathrm{O}$, and $\mathrm{CO}_{2}$ in the lowermost stratosphere. They also found realistic correlations between $\mathrm{O}_{3}$ and $\mathrm{CO}$ near the extratropical tropopause.

Ozone is an important species to represent well in the NTR, due to its central role in upper tropospheric chemistry (e.g., Müller and Brasseur, 1999), and its effect on the radiative balance of the atmosphere. Lacis et al. (1990) found the highest sensitivity of surface temperatures to changes in ozone near the tropopause, due to the large temperature contrast between the NTR and the surface. Typically, modeled NTR ozone mixing ratios are substantially higher than observed, particularly just below the tropopause (e.g., Wauben et al., 1998; Rotman et al., 2004). This would obviously overweight the radiative impact of the NTR on surface temperatures in chemistry-climate models with this defect.

Here we exploit the high vertical resolution of ozonesonde data to evaluate how well the GMI Combo model is able to reproduce NTR ozone distributions. We explore the mechanisms responsible for any deficiencies that we find. We focus on a climatological evaluation due to the GCM source of the meteorological data used to drive the GMI CTM. Following Logan (1999a), we construct climatological monthly average ozone profiles from the ozonesonde data. The 23-station climatology exploits the availability of a now-substantial number of tropical sondes from the SHADOZ network (Thomson et al., 2003a) to more fully represent the tropics than has been previously possible. The number of sondes at each station is sufficient to define monthly means and medians precisely enough to allow an evaluation of the accuracy of the model results.

We also investigate the effects and importance of averaging relative to the tropopause versus averaging at constant pressure levels to create the monthly profiles from daily ozonesondes. Averaging relative to the tropopause was shown by Logan (1999a) to substantially increase crosstropopause vertical gradients in monthly averages. How this affects a model/measurement intercomparison has not yet been thoroughly investigated.

In Sect. 2 we describe the ozonesonde climatologies constructed for this comparison. The GMI Combo model is described in Sect. 3. Section 4 presents comparisons between modeled distributions and the climatologies. We summarize these results and draw conclusions in Sect. 5.

\section{Ozonesonde data set description}

The ozonesonde data were analyzed in a manner similar to that described in Logan (1999a). She presented monthly averages for ozone on standard pressure levels, and on an altitude grid relative to the height of the thermal tropopause. At the time, data were available for only two tropical sonde stations. Here we use data from 10 tropical stations in the Southern Hemisphere Additional Ozonesondes (SHADOZ) network (Thompson et al., 2003a), which started in 1998; two of these are in the northern hemisphere (NH). We use data from 12 extratropical stations in the NH. Station details are given in Table 1 and shown in Fig. 1.

The analysis was the same as that in Logan (1999a) with the following differences: the base period for the analysis was updated to 1985-2000 for the extratropical stations, and to all available data for the tropical stations, which have shorter records. The pressure levels were changed from irregular intervals $(1000,900,800 \mathrm{hPa}$ etc. $)$ to 35 levels equally spaced in pressure altitude between 1000 and $5 \mathrm{hPa}$ ( $\sim 1 \mathrm{~km}$ apart). Level averages were formed for each pressure level using all measurements within a month located within the pressure layer, with interpolation used only if there were 
no measurements in a layer. This last change was made because the data are now available with much higher vertical resolution than previously, when the poor resolution required that interpolation be used.

Exactly the same profiles were used to form the monthly means on the pressure levels and on the altitude grid relative to the thermal tropopause. Some profiles were eliminated from the analysis as the tropopause levels derived from the temperature profiles were clearly unrealistic, as discussed in Logan (1999a). The data relative to the tropopause were interpolated to a grid with $1 \mathrm{~km}$ resolution in geometric altitude, extending from $6 \mathrm{~km}$ below the tropopause to $12 \mathrm{~km}$ above it. These profiles were averaged together to produce monthly means relative to the tropopause, the RTT climatology. There are about 150 profiles in the monthly means for the European sonde stations, about 80 for the other extratropical stations, and about 22 for the tropical stations.

Several factors motivated the choice to use the thermal tropopause as a reference. Temperature is simultaneously measured with ozone for each sonde, providing a straightforward and high-resolution profile enabling accurate identification of the thermal tropopause. Use of a dynamical tropopause definition based on potential vorticity (PV) would require interpolating relatively low vertical and horizontal resolution PV fields from one of several available analyzed data sets to the sonde profiles. Pan et al. (2004) found that the chemical transition layer surrounding the tropopause defined by $\mathrm{CO}$ and $\mathrm{O}_{3}$ correlations centered on the thermal tropopause, also supporting the use of the thermal tropopause.

\section{Model and run description}

The GMI Combo model is described in Duncan et al. (2007) and Strahan et al. (2007). The basic structure of the Combo model, without photochemical modules, is also given in Considine et al. (2005). Here, we present details salient to this study. The Combo model is an outgrowth of the original GMI model, a stratospheric CTM described in Rotman et al. (2001). The complete Combo model also includes a full treatment of both stratospheric and tropospheric photochemistry. In this study, we run the Combo model at horizontal resolutions of $4^{\circ}$ latitude by $5^{\circ}$ longitude and $2^{\circ}$ by $2.5^{\circ}$. The model has 42 levels, extending from the surface up to $0.01 \mathrm{hPa}$. The resolution at the tropopause is about $1.1 \mathrm{~km}$. This is comparable to other models of this type (e.g., Rotman et al., 2004; Kinnison et al., 2007).

For this study, the Combo model was driven by meteorological data generated from a 50-year run of the GMAO GEOS4 AGCM (Bloom et al., 2005). This run was driven by observed sea surface temperatures, but was otherwise unconstrained. We use a 5-year subset corresponding to the years 1994-1998. The GEOS4 AGCM has both deep (Zhang
Table 1. Ozonesonde stations, locations, and data span. The table gives the names of the stations providing data used in this paper, the geographic location of the station, and the span of time of observations used in this paper.

\begin{tabular}{lrrr}
\hline Station Name & Latitude & Longitude & Data Record \\
\hline Resolute & 75 & -95 & $01 / 85-12 / 00$ \\
Churchill & 59 & -147 & $01 / 85-12 / 00$ \\
Goose Bay & 53 & -60 & $01 / 85-12 / 00$ \\
Edmonton & 53 & -114 & $01 / 85-12 / 00$ \\
Uccle & 51 & 4 & $01 / 85-12 / 00$ \\
Hohenpeissenberg & 48 & 11 & $01 / 85-12 / 00$ \\
Payerne & 47 & 7 & $01 / 85-12 / 00$ \\
Sapporo & 43 & 141 & $01 / 85-12 / 00$ \\
Boulder & 40 & -105 & $01 / 85-12 / 00$ \\
Wallops Island & 38 & -76 & $01 / 85-12 / 00$ \\
Tateno & 36 & 140 & $01 / 85-12 / 00$ \\
Paramaribo & 6 & -55 & $09 / 99-12 / 04$ \\
Kuala Lumpur & 3 & 102 & $01 / 98-12 / 04$ \\
San Cristobal & -1 & -90 & $03 / 98-12 / 04$ \\
Nairobi & -1 & 37 & $09 / 97-12 / 04$ \\
Malindi & -3 & 40 & $03 / 99-12 / 04$ \\
Natal & -6 & -35 & $01 / 98-12 / 04$ \\
Java & -8 & 113 & $01 / 98-12 / 04$ \\
Ascension & -8 & -15 & $07 / 90-12 / 04$ \\
Samoa & -14 & -170 & $08 / 95-12 / 04$ \\
Fiji & -18 & 178 & $02 / 97-12 / 04$ \\
Reunion Island & -21 & 55 & $01 / 98-12 / 04$ \\
Pretoria & -26 & 28 & $07 / 90-12 / 04$ \\
\hline
\end{tabular}

and McFarlane, 1995) and shallow (Hack, 1994) convective transport parameterizations.

The Combo model uses a 114-species chemical mechanism combining the stratospheric mechanism of Douglass et al. (2004) with the tropospheric chemical mechanism of Bey et al. (2001). Species transport is calculated using the fluxform semi-Lagrangian scheme of Lin and Rood (1996). The chemical mechanism describes both stratospheric halogen chemistry and tropospheric nonmethane hydrocarbon chemistry, including isoprene oxidation (Horowitz et al., 1998). Both stratospheric and tropospheric heterogeneous reactions are included in the chemical mechanism. PSCs are parameterized using the scheme of Considine et al. (2000). Tropospheric heterogeneous reactions occur on tropospheric sulfate, dust, sea-salt, and organic and black carbon aerosol distributions generated by the Goddard Chemistry, Aerosol, Radiation and Transport model (Chin et al., 2002).

Mixing ratio boundary conditions for stratospheric source gases, $\mathrm{N}_{2} \mathrm{O}$, and $\mathrm{CH}_{4}$ correspond to the mid-1990's. Surface emission inventories are described in Bey et al. (2001) and Duncan et al. (2003), and represent rates typical of the mid1990's. Lightning $\mathrm{NO}_{\mathrm{x}}$ is also included as monthly mean emissions fields. The lightning source is $5.0 \mathrm{TgN} / \mathrm{y}$. The horizontal distribution of lightning emissions is based on the 

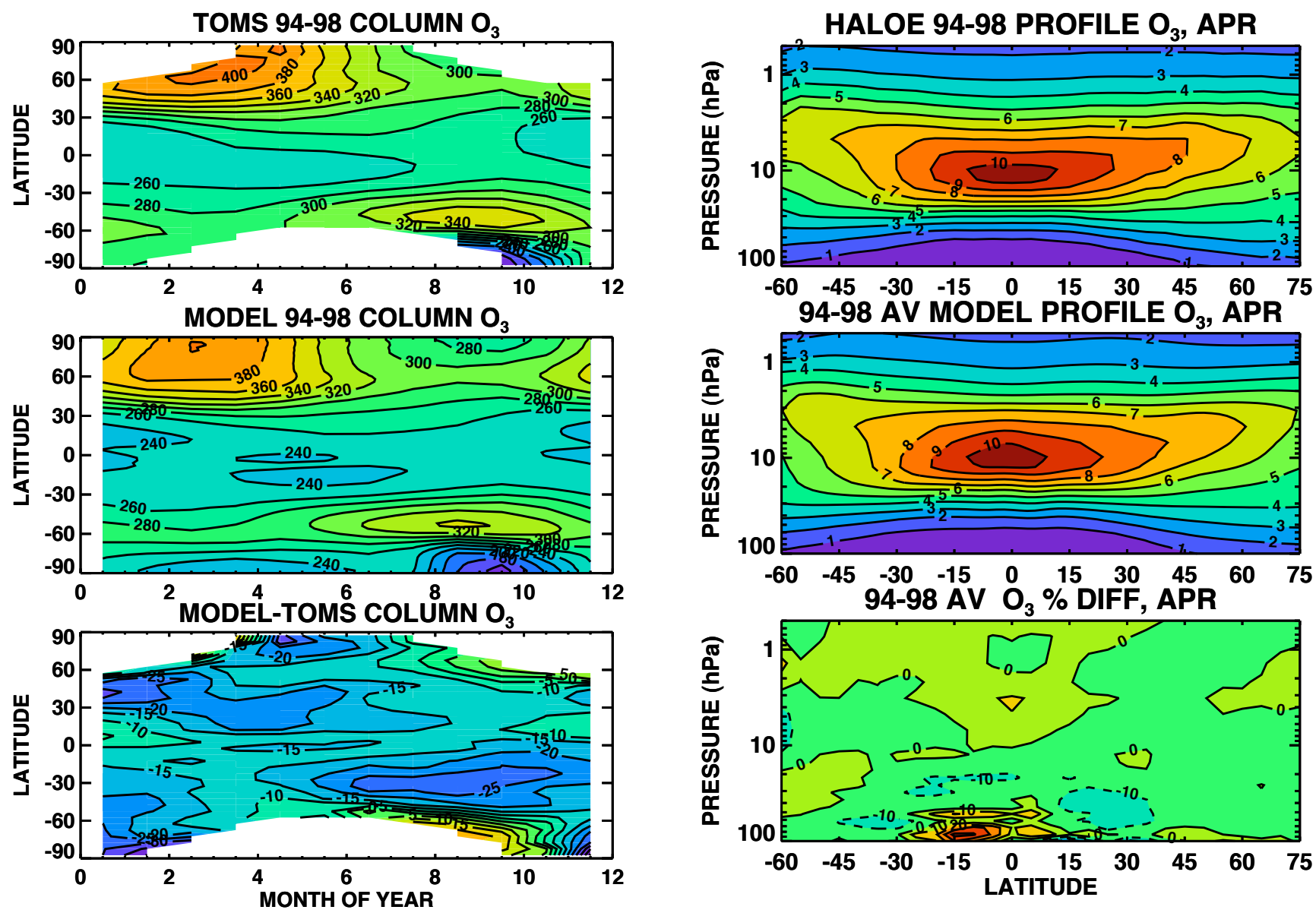

Fig. 2. Top panel: 1994-1998 average zonal mean total ozone from the Total Ozone Mapping Spectrometer merged ozone dataset, as function of time of year and latitude. Middle panel: 1994-1998 average zonal mean total ozone from the GMI combined model, as function of time of year and latitude. Bottom panel: Model observed differences, in Dobson units.

Fig. 3. Top panel: Zonal mean ozone distribution from version 19 Halogen Occultation Experiment (HALOE) data gathered during April for the years 1994-1998, as function of latitude and pressure in $\mathrm{hPa}$. Middle panel: GMI combined model zonal mean ozone, averaged for Aprils from 1994-1998 as function of latitude and pressure. Bottom panel: Percent difference of April zonal mean modeled ozone distribution from observed ozone distribution, in percent. Contour levels: $0 \%, \pm 10 \%, \pm 20 \%, \ldots$.

\section{Results}

ISCCP deep convective cloud climatology as described in Price et al. (1997). Lightning flash rates are from Price and Rind (1992), and the vertical distribution of lightning $\mathrm{NO}_{\mathrm{x}}$ is based on the cloud resolved convection simulations of Pickering (1998).

The initial condition was taken from a 10 -year spinup run of the Combo model, which is enough time for stratospheric species to converge to an approximate annually repeating steady-state condition well above the lower stratosphere, the focus of this study. Diurnal average 3-D gridded ozone distributions were output daily. These were interpolated to the ozonesonde station locations, and used to construct the monthly average profiles we compare to observations in the next section.

\subsection{Global comparisons}

We first provide a global-scale perspective for subsequent comparisons with the ozonesonde climatologies. Figure 2 compares model column ozone distributions from the $2^{\circ} \times 2.5^{\circ}$ model run throughout the year with 1994 1998 average column ozone from the merged Total Ozone Mapping Spectrometer (TOMS)/Solar Backscatter Ultraviolet (SBUV) measurement data set (Stolarski and Frith, 2006). The model reproduces well the observed average global total ozone distribution during this time period. The annual cycle of tropical total ozone is represented well, though model values are about $20 \mathrm{DU}$ low compared to the TOMS observations. The model $\mathrm{NH}$ springtime peak of $\sim 400 \mathrm{DU}$ is a few DU low, occurs $\sim 2$ weeks early, and is not distinctly off the 

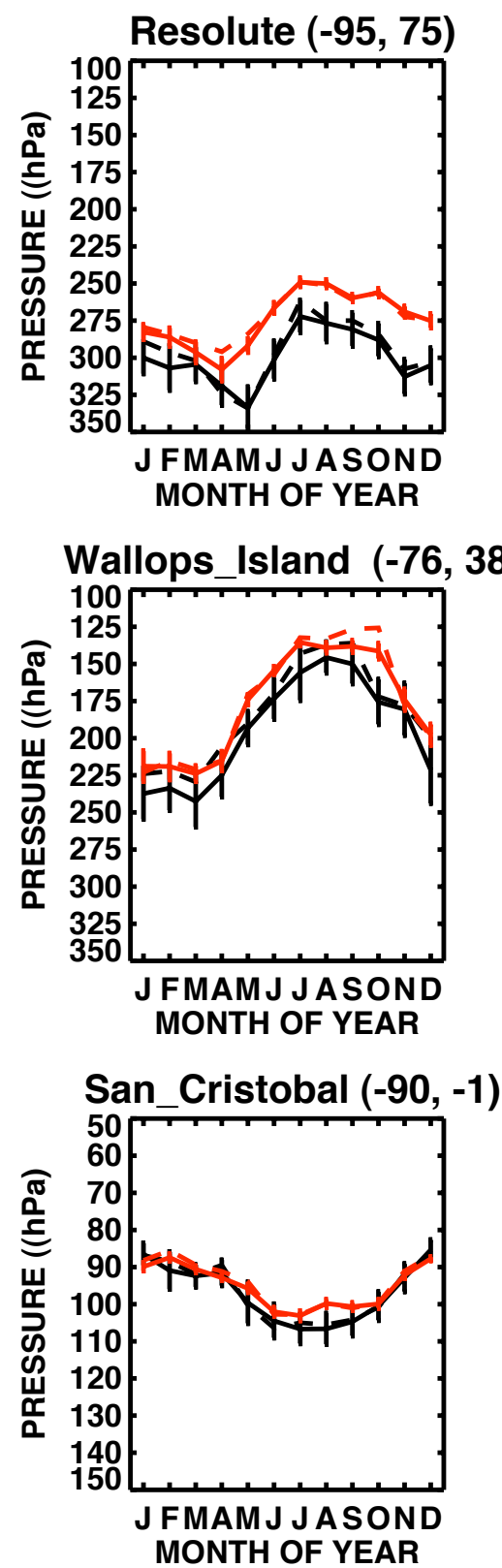
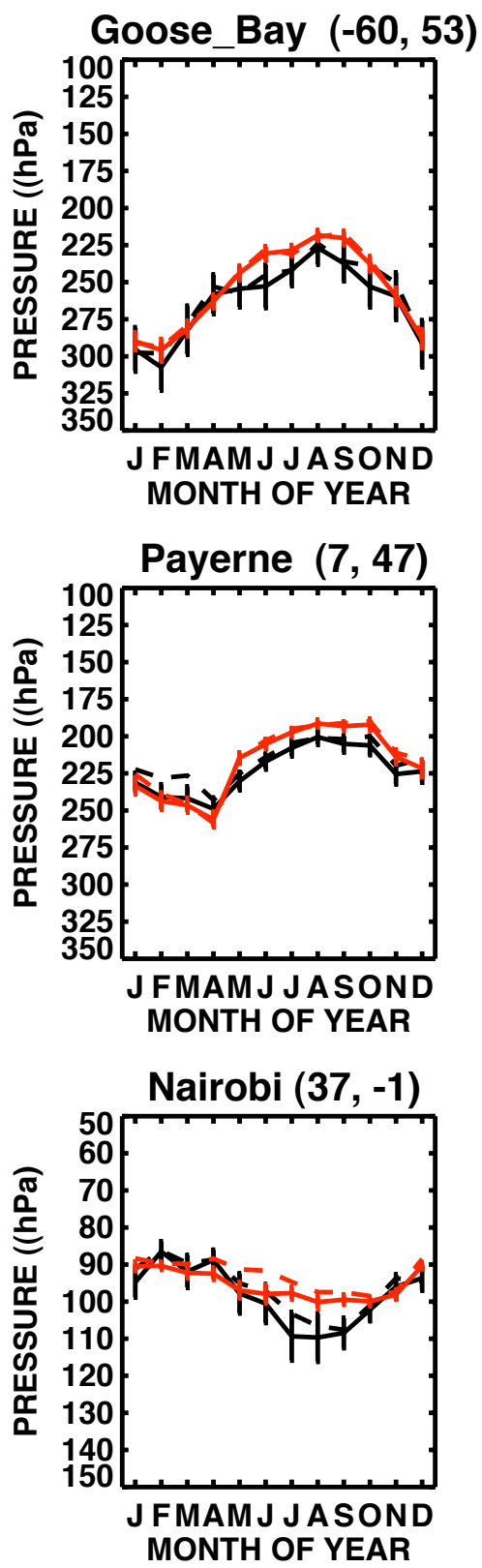
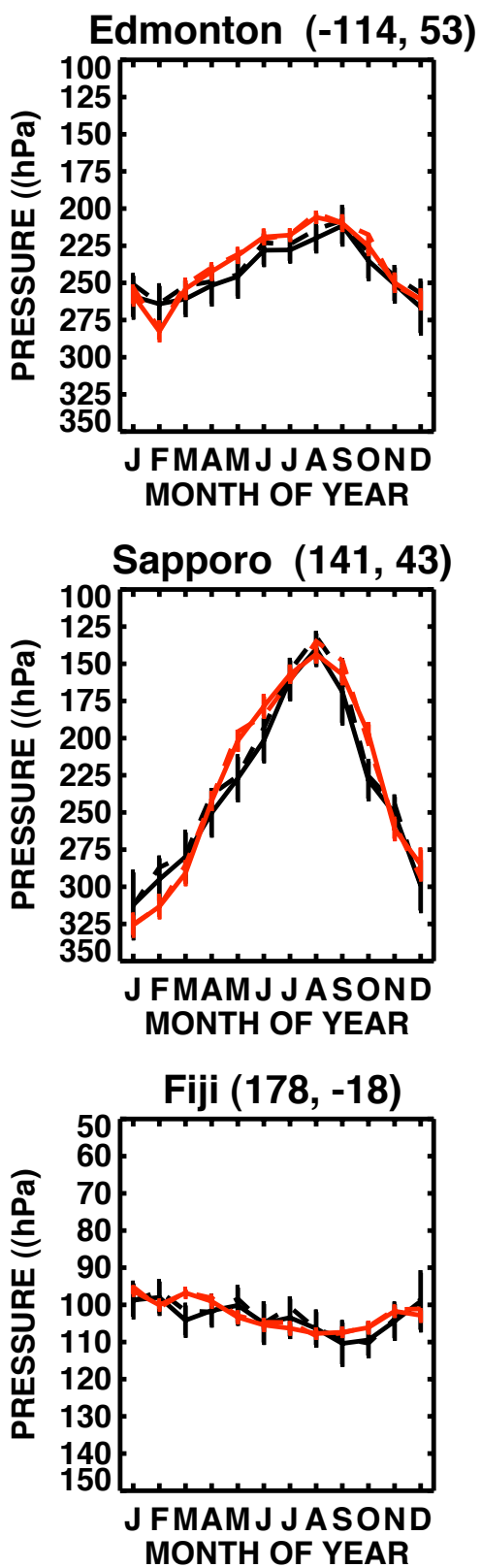

Fig. 4. Comparison of GMI combined model (red lines) and observed (black lines) monthly mean (solid lines) and median (dashed lines) tropopause pressures as function of time of year at six Northern Hemisphere stations and three stations in the Southern Hemisphere tropics. Vertical bars on model mean indicate \pm two times standard error of the monthly mean values. Note inverted pressure axis. The station name and location is given in title of each panel of the figure.

pole as is the case with the observations. The NH high latitude summertime ozone decrease is reproduced well. In the $\mathrm{SH}$, the model area over $340 \mathrm{DU}$ is smaller than observed, resulting in model $\mathrm{O}_{3}$ about $25 \mathrm{DU}$ low, but is otherwise in good agreement. The model produces a slightly weaker but well-timed ozone hole. Low model values at high latitudes during the SH summer suggest a somewhat too-isolated SH polar region during the spring and summer. Since total ozone is very sensitive to the stratospheric residual circulation, the good agreement between observed and modeled total ozone, in particular the lack of a strong latitudinal gradient in model differences from observations shown in the third panel of Fig. 2, suggests that the stratospheric residual circulation of the GEOS-4 AGCM is fairly realistic.

Figure 3 compares the model zonal mean distribution of stratospheric ozone in April from the $2^{\circ} \times 2.5^{\circ}$ model run 
with observations made during April by the Halogen Occultation Experiment (HALOE) on board the Upper Atmosphere Research Satellite (UARS) between 1994 and 1998 (Russell et al., 1993). The figure shows excellent correspondence between the observations and the model throughout most of the stratosphere. The model is generally within $10 \%$ of observations. There is a high-bias of up to $30 \%$ in the tropical lower stratosphere compared to HALOE observations, which will be discussed further below. Overall, the comparison reveals no serious deficiencies in the model representation of stratospheric ozone distributions.

The $4^{\circ} \times 5^{\circ}$ model run also compares very well with the merged total ozone and HALOE data (not shown). The differences that exist, such as a shallower ozone hole and somewhat larger model high-biases in the tropical lower stratosphere, are generally minor in this global perspective.

\subsection{Tropopause heights}

As a test of model meteorological characteristics in the NTR, we first compare modeled and observed thermal tropopause heights at selected stations in Fig. 4. As we discuss in Section 2 above, we use the thermal tropopause because high vertical resolution temperature data for each ozonesonde is available which allows the thermal tropopause to be reliably identified. The observed tropopause values in Fig. 4 are from the RTT climatology, not the pressure-averaged climatology, calculated as described in Sec. 2. To find the tropopause height for a model daily profile, we first interpolated the profile to a $0.1 \mathrm{~km}$ grid using cubic splines and then applied the WMO (1957) criterion for tropopause height. The corresponding pressure values were combined to construct the monthly means and medians shown in Fig. 4. Solid lines show monthly mean values, dashed lines show monthly medians. Fig. 4 includes $\pm 2 \sigma$ standard error bars for both modeled and observed values. These indicate that the means and medians have been defined precisely enough for meaningful comparisons. (Note that the smallness of the model error compared to the error in the sonde climatology does not reflect differences in variability, which is comparable to observations, but is due to the typically larger number of model values used to calculate the means and medians.) The stations were chosen to span the latitude range of the observations and show typical results. The differences between monthly mean and median tropopause heights are small at all stations in both the observations and the model. There is good agreement between modeled and observed tropopause pressures, including the annual cycle. Differences are largest at Resolute $\left(75^{\circ} \mathrm{N}\right)$ and at Wallops Island $\left(38^{\circ} \mathrm{N}\right)$.

Table 2 provides a summary of the comparisons for all stations. The model tropopause is typically at slightly lower pressures than observed, except for Uccle, Paramaribo, Java, and Reunion Island. There is anomalously poor agreement at Tateno $\left(36^{\circ} \mathrm{N}\right)$, with model pressures $\sim 21 \%$ lower than observations. This is primarily a consequence of tempera- ture profiles with double tropopauses, which sometimes occur near the subtropical jet. Due to this poor agreement, we exclude Tateno from further analysis.

\subsection{Tropopause ozone}

Figure 5 compares for the $4^{\circ} \times 5^{\circ}$ model run the annual cycle of observed monthly mean tropopause ozone (black line) with model monthly mean tropopause ozone (red line) and model ozone values sampled at observed tropopause altitudes (blue line). Ozone at the model tropopause is higher than observed values, both in the tropics and NH extratropics and throughout the year. Figure 5 shows that the model high bias is occasionally due simply to a higher tropopause in the model than observations - for instance, at Resolute after March. However, at most other locations model ozone is high-biased even at the observed tropopause. Figure 5 also shows that the annual cycle of model tropopause ozone is generally similar in phasing to the observations. The absolute magnitude of the annual cycle in the model at these locations is also similar to the observations, though in percentage terms the annual cycles are somewhat weaker than is observed.

Figure 6 shows results for the $2^{\circ} \times 2.5^{\circ}$ run. The tropopause ozone bias in the extratropics is largest during the spring and summer. At Resolute, Goose Bay, and Edmonton, peak ozone values are about $75 \mathrm{ppbv}$ higher than the $4^{\circ} \times 5^{\circ}$ run. At Payerne and Sapporo, there are smaller increases of $\sim 30$ ppbv. The tropical stations show a smaller ozone high bias compared to the $4^{\circ} \times 5^{\circ}$ run.

Figure 7 shows the percent difference between modeled and observed annually averaged tropopause ozone for all stations, as a function of station latitude. Results for both the $4^{\circ} \times 5^{\circ}$ and $2^{\circ} \times 2.5^{\circ}$ model runs are shown. In the extratropics $\left(38^{\circ}-75^{\circ} \mathrm{N}\right)$, where annual mean tropopause ozone is $116-149$ ppbv, the model has a high bias of $36-72 \%$ in the $4^{\circ} \times 5^{\circ}$ run (mean $45 \%$ ). The extratropical high bias in the $2^{\circ} \times 2.5^{\circ}$ model run is significantly larger, with the mean bias increasing to $\sim 61 \%$. However, there are reductions for Boulder and Wallops Island, the two lowest-latitude midlatitude stations considered. In the tropics, observed annual mean tropopause ozone is $58-130 \mathrm{ppbv}$. The $4^{\circ} \times 5^{\circ}$ run shows a high bias of $17-63 \%$ (mean $43 \%$ ) in the tropics. This drops to $\sim 31 \%$ in the $2^{\circ} \times 2.5^{\circ}$ model run.

The fact that model tropopause high biases are larger in the $2^{\circ} \times 2.5^{\circ}$ run at midlatitude stations, and smaller in the tropics, may be explained by lower effective horizontal diffusion in the higher resolution run. Strahan and Polansky (2006) showed that simulations at $2^{\circ} \times 2.5^{\circ}$ better resolved the stratospheric subtropical and polar mixing barriers, leading to larger horizontal gradients and improving the simulation of stratospheric dynamical features. Reduced horizontal mixing between the tropics and the midlatitudes would tend to decrease tropical mixing ratios and increase those at mid and higher latitudes. Thus, the improved model 

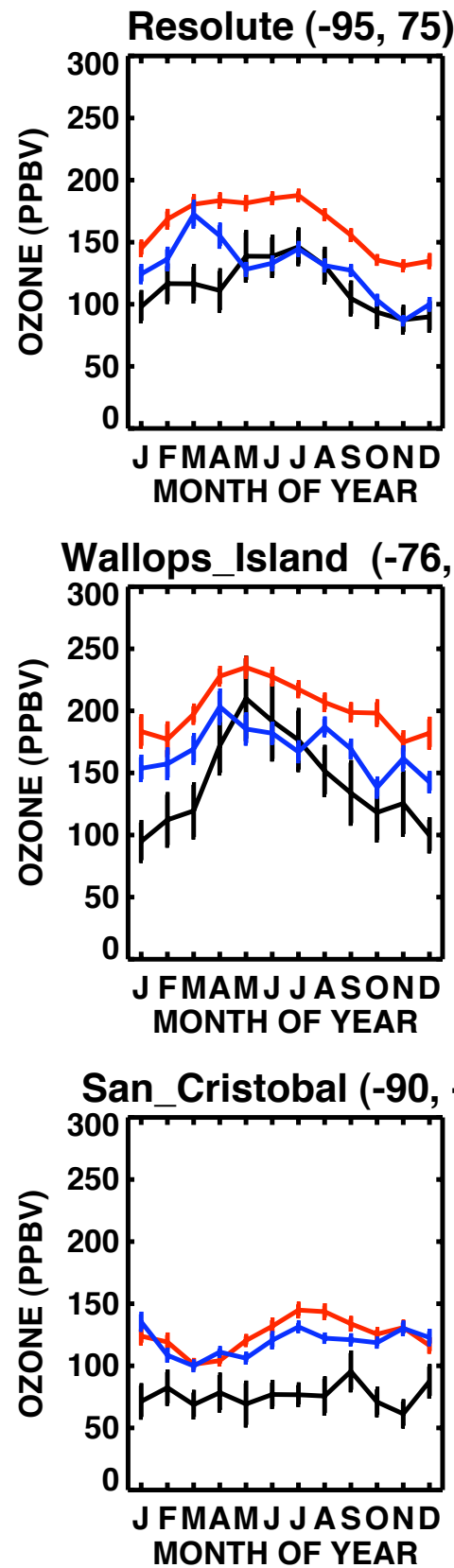
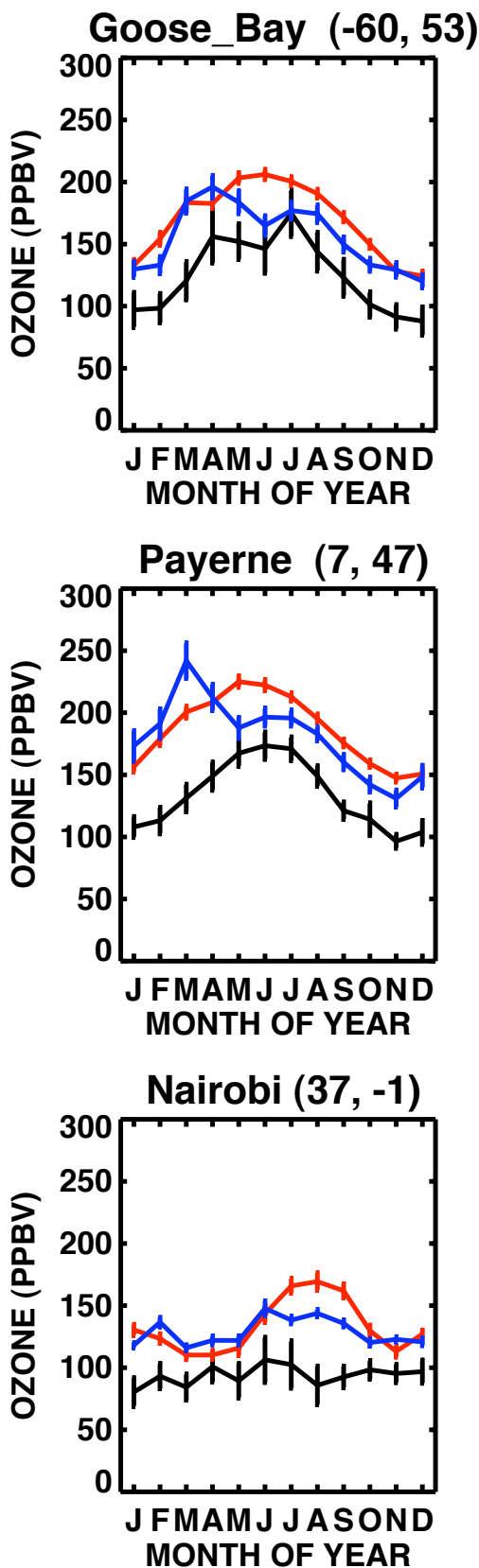
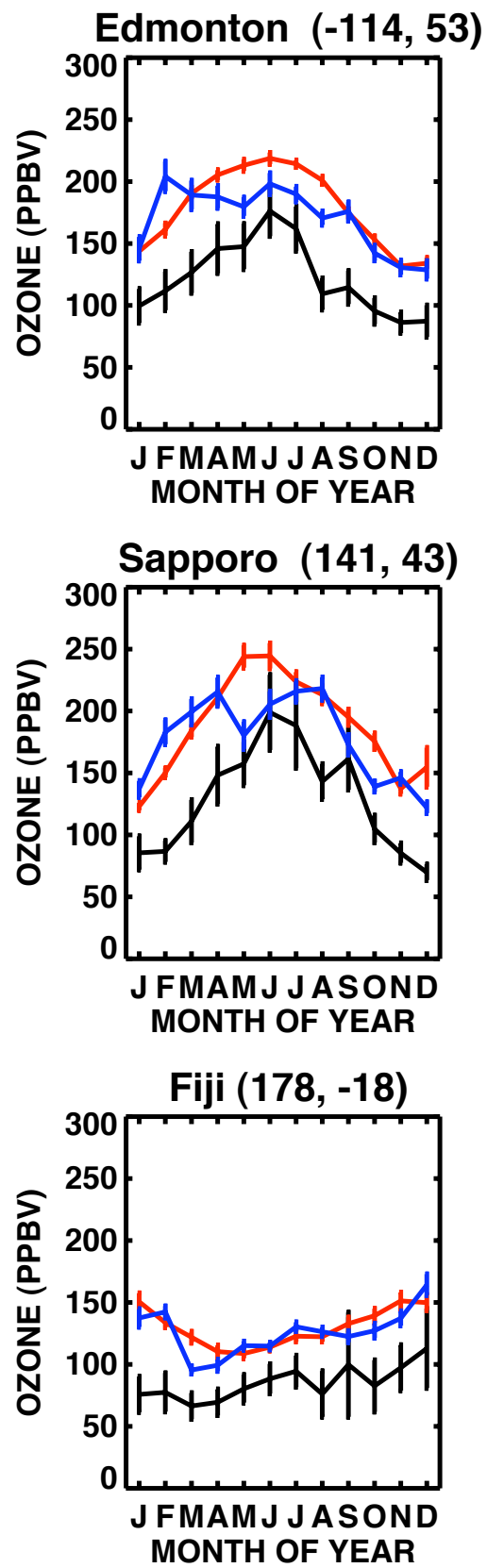

Fig. 5. Comparison of annual cycle of GMI Combo model monthly mean tropopause ozone (red lines), Combo model ozone at the observed tropopause (blue lines), and observed tropopause ozone (black lines) at six Northern Hemisphere stations and three stations in the Southern Hemisphere tropics. Ozone units are parts per billion by volume. The vertical bars on the lines indicate \pm 2 times the standard error. Model resolution is $4^{\circ} \times 5^{\circ}$.

resolution appears to have removed an error (high horizontal diffusivity) that was compensating for a second error which is responsible for high biases at the extratropical model tropopause.

A possible explanation for the ozone high bias at the tropopause seen in both simulations is an overly vigorous residual circulation in the GEOS 4 AGCM. Strahan et al. (2007) found overly strong ascent and mixing in the
GEOS 4 AGCM tropical lower stratosphere, particularly during the fall, suggesting that the residual circulation may be too strong. Since according to Olsen et al. (2007) the residual circulation is strongly correlated with stratospheretroposphere exchange, we performed linear regressions of the 60 ( 5 years at 12 months/year) zonal mean, monthly mean $\mathrm{O}_{3}$ values at each $\mathrm{NH}$ latitude and pressure level in the $4^{\circ} \times 5^{\circ}$ run of the Combo model with the 60 values of monthly mean 

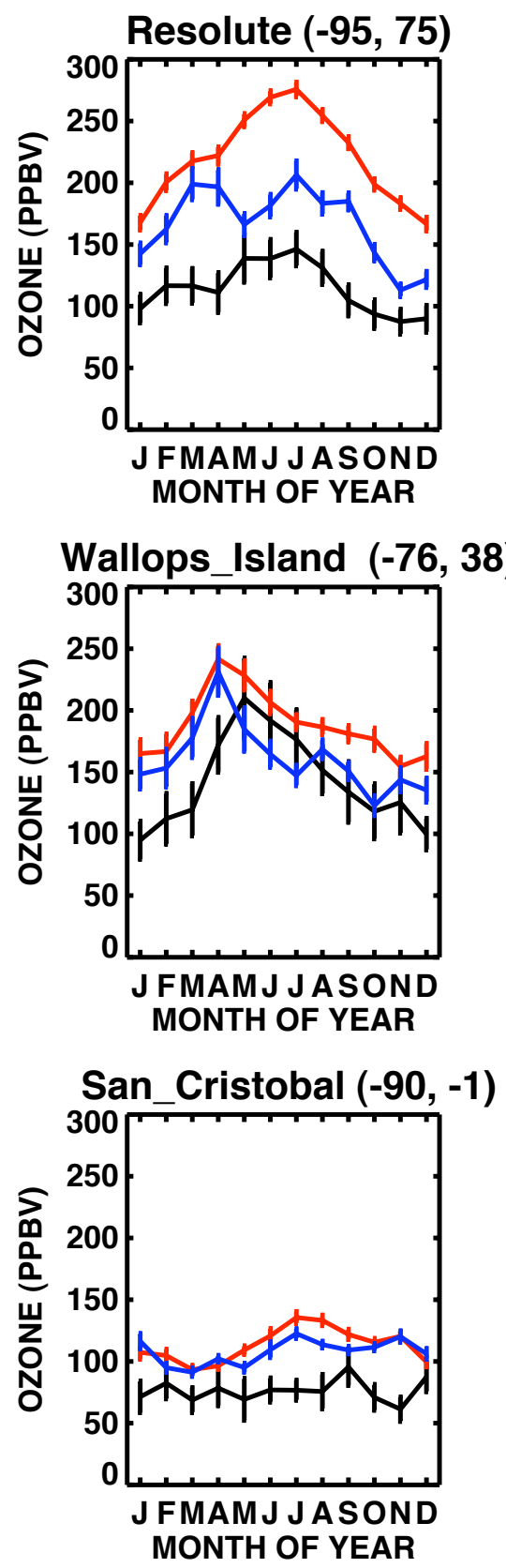
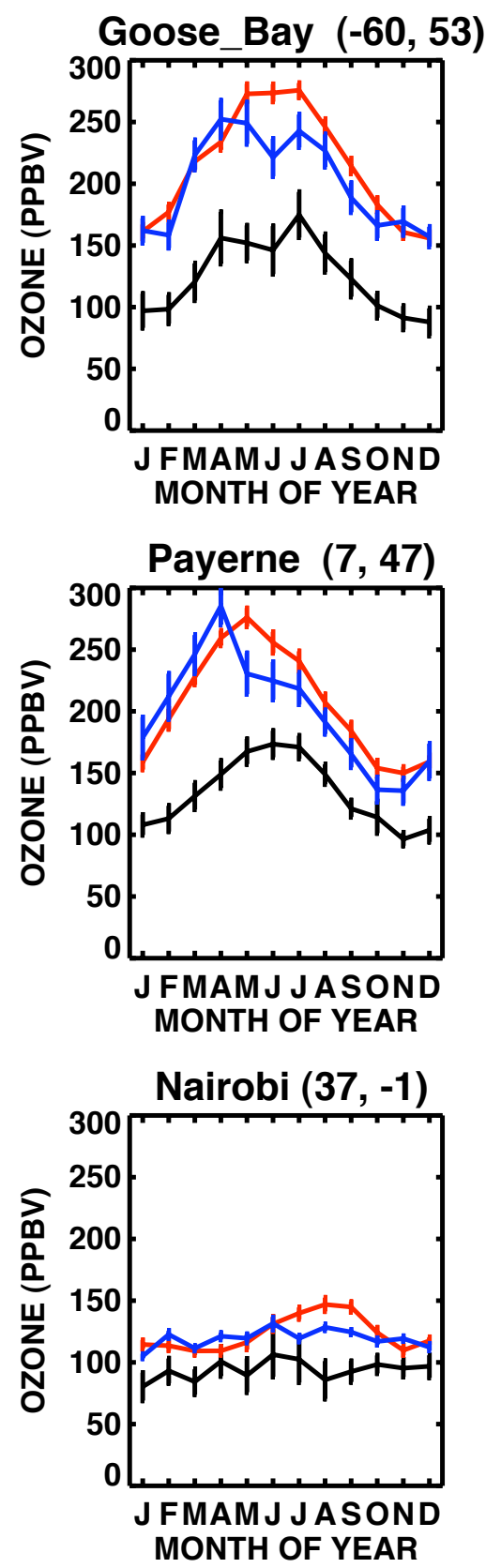
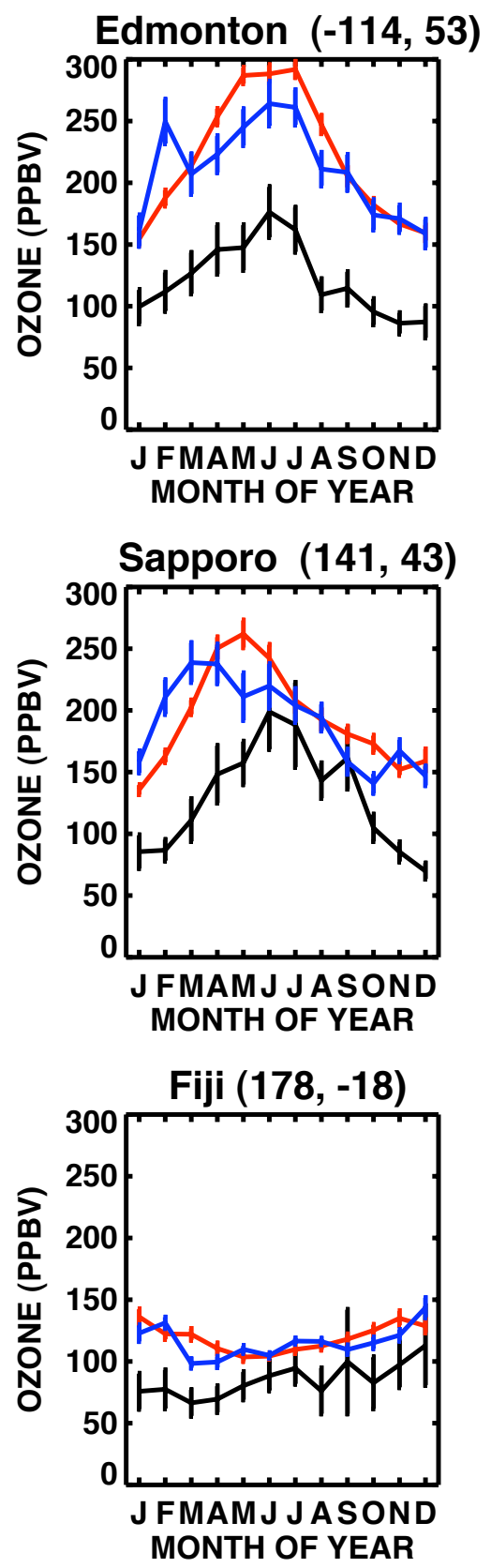

Fig. 6. Same as Fig. 5, except for $2^{\circ} \times 2.5^{\circ}$ run.

$\mathrm{NH}$ extratropical cross-tropopause $\mathrm{O}_{3}$ flux, calculated as described in Olsen et al. (2004). (Briefly, the $\mathrm{O}_{3}$ flux across the tropopause is calculated as the difference between the flux crossing the $380 \mathrm{~K}$ potential temperature surface and the change in $\mathrm{O}_{3}$ in the lowermost stratosphere.) From these regressions we calculated at each latitude and pressure level the linear correlation and fractional sensitivity (percent change in $\mathrm{O}_{3}$ per percent change in flux) of zonal mean, monthly mean $\mathrm{O}_{3}$ with the monthly mean $\mathrm{NH}$ cross-tropopause flux of $\mathrm{O}_{3}$. This is shown in Fig. 8. The top panel of Fig. 8 shows that $\mathrm{O}_{3}$ near the tropopause is strongly positively cor- related with STE poleward of $\sim 30^{\circ}$. (Note that for 60 points, the probability that a correlation of more than 0.5 occurs by chance is less than $0.05 \%$ ). The correlation remains high throughout most of the extratropical stratosphere. The bottom panel suggests that a $1 \%$ increase in STE results in an $\sim 0.5-0.6 \%$ increase in tropopause $\mathrm{O}_{3}$. Given the $\mathrm{NH}$ mean high bias of $\sim 45 \%$, Fig. 8 suggests that a reduction in STE of $\sim 90 \%$ would be required to eliminate the model high bias at the tropopause in the NH.

Model stratosphere-to-troposphere exchange of NH extratropical $\mathrm{O}_{3}$ in the $4^{\circ} \times 5^{\circ}$ run is $266 \pm 9 \mathrm{Tg} \mathrm{yr}^{-1}$, which agrees 
Table 2. Characteristics of observed and modeled thermal tropopause heights at observation locations. Column 1: Observed annual mean tropopause pressure, in hPa. Column 2: Model annual mean tropopause pressure, in hPa. Column 3: percent difference of model from observed annual mean tropopause pressure. Columns 4 and 5: Amplitude of observed and modeled annual cycles, respectively, as percent of annual mean value. Columns 6 and 7: Observed and modeled month of minimum tropopause pressure (maximum tropopause altitude).

\begin{tabular}{lccccccc}
\hline Station Name & $\begin{array}{c}\text { Observed } \\
\text { Annual Mean } \\
\text { Tropopause } \\
\text { Pressure }\end{array}$ & $\begin{array}{c}\text { Model } \\
\text { Annual Mean } \\
\text { Tropopause } \\
\text { Pressure }\end{array}$ & $\begin{array}{c}\text { Difference } \\
(\%)\end{array}$ & $\begin{array}{c}\text { Observed } \\
\text { Annual } \\
\text { Amplitude }\end{array}$ & $\begin{array}{c}\text { Model } \\
\text { Annual } \\
\text { Amplitude }\end{array}$ & $\begin{array}{c}\text { Obs. } \\
\text { Max } \\
\text { Month }\end{array}$ & $\begin{array}{c}\text { Model } \\
\text { Max } \\
\text { Month }\end{array}$ \\
\hline Resolute & 300.09 & 273.53 & -8.85 & 20.47 & 19.04 & 7 & 7 \\
Churchill & 273.52 & 258.92 & -5.34 & 25.74 & 23.10 & 7 & 7 \\
Goose Bay & 263.33 & 253.84 & -3.60 & 30.59 & 28.99 & 8 & 8 \\
Edmonton & 243.42 & 238.11 & -2.18 & 22.50 & 31.56 & 9 & 8 \\
Uccle & 229.96 & 230.95 & 0.43 & 17.66 & 26.70 & 8 & 8 \\
Hohenpeissenberg & 227.97 & 222.77 & -2.28 & 18.30 & 28.83 & 9 & 8 \\
Payerne & 223.24 & 218.01 & -2.34 & 21.68 & 28.47 & 8 & 8 \\
Sapporo & 234.45 & 227.48 & -2.97 & 73.47 & 78.33 & 8 & 8 \\
Boulder & 196.53 & 182.18 & -7.30 & 57.06 & 54.00 & 8 & 8 \\
Wallops Island & 194.53 & 176.14 & -9.46 & 49.80 & 49.96 & 8 & 7 \\
Tateno & 194.19 & 154.34 & -20.53 & 90.83 & 69.85 & 8 & 8 \\
Paramaribo & 99.18 & 99.99 & 0.82 & 19.67 & 14.76 & 2 & 12 \\
Kuala Lumpur & 103.24 & 102.99 & -0.24 & 18.91 & 15.66 & 5 & 5 \\
San Cristobal & 96.85 & 95.29 & -1.62 & 22.03 & 16.35 & 12 & 12 \\
Nairobi & 98.31 & 95.75 & -2.61 & 23.55 & 10.55 & 2 & 12 \\
Malindi & 99.21 & 96.50 & -2.74 & 26.80 & 11.98 & 3 & 1 \\
Natal & 99.32 & 97.05 & -2.28 & 15.19 & 15.55 & 2 & 5 \\
Java & 100.20 & 100.96 & 0.77 & 16.86 & 10.00 & 12 & 5 \\
Ascension & 99.62 & 93.51 & -6.13 & 18.03 & 10.62 & 1 & 2 \\
Samoa & 101.34 & 100.66 & -0.67 & 11.97 & 11.17 & 1 & 1 \\
Fiji & 103.38 & 102.82 & -0.54 & 11.99 & 10.96 & 2 & 1 \\
Reunion Island & 102.25 & 104.61 & 2.31 & 16.81 & 7.91 & 2 & 5 \\
Pretoria & 119.24 & 111.28 & -6.68 & 48.25 & 13.55 & 1 & 3 \\
\hline
\end{tabular}

well with several other estimates (Olsen et al., 2004). A 90\% reduction is therefore unreasonable. Changes to the residual circulation of the magnitude necessary to reduce STE by $90 \%$ would also adversely affect the good agreement of stratospheric $\mathrm{O}_{3}$ with observations shown in Figs. 2 and 3, in addition to increasing the tropical tropopause ozone high bias. Thus Fig. 8 does not support the idea that the ozone high biases at the model tropopause can be explained simply by an overly vigorous residual circulation and consequently too much STE. Additional evidence for the soundness of the GEOS4 AGCM meteorological data is provided in Strahan et al. (2007), which demonstrates that transport processes connecting the tropical lower and upper troposphere, and between the tropical UT and the extratropical lowermost stratosphere are represented correctly.

Other possible contributors to the model high bias include insufficient convection, insufficient vertical resolution at the tropopause and an overly vertically diffusive transport scheme. We tested the effects of model convective processes by conducting a simulation with convection turned off. This only increased tropopause $\mathrm{O}_{3}$ values by $\sim 5 \%$ in the extrat- ropics, and $\sim 10 \%$ in the tropics, indicating that insufficient convection is not a likely explanation. Rasch et al. (2006) demonstrated that the Lin and Rood transport scheme used in the Combo model is substantially less vertically diffusive than other popular schemes for simulating tracer transport in the NTR. Thus it is most likely that higher vertical resolution in the NTR is necessary to eliminate the high bias of tropopause ozone.

\subsection{Effects of averaging method on ozone gradients}

In making comparisons of the observed and modeled vertical distribution of ozone, we consider two approaches: a pressure coordinate and a vertical coordinate defined relative to the tropopause. We illustrate the differences between the two averaging methods in Fig. 9. Figure 9a shows as a function of pressure the 49 sonde profiles in the climatologies sampled at Edmonton for Januarys between 1985 and 2000 (red lines), the monthly average vertical profile averaged at constant pressure levels, and one standard deviation error profiles (black lines). The figure shows that 


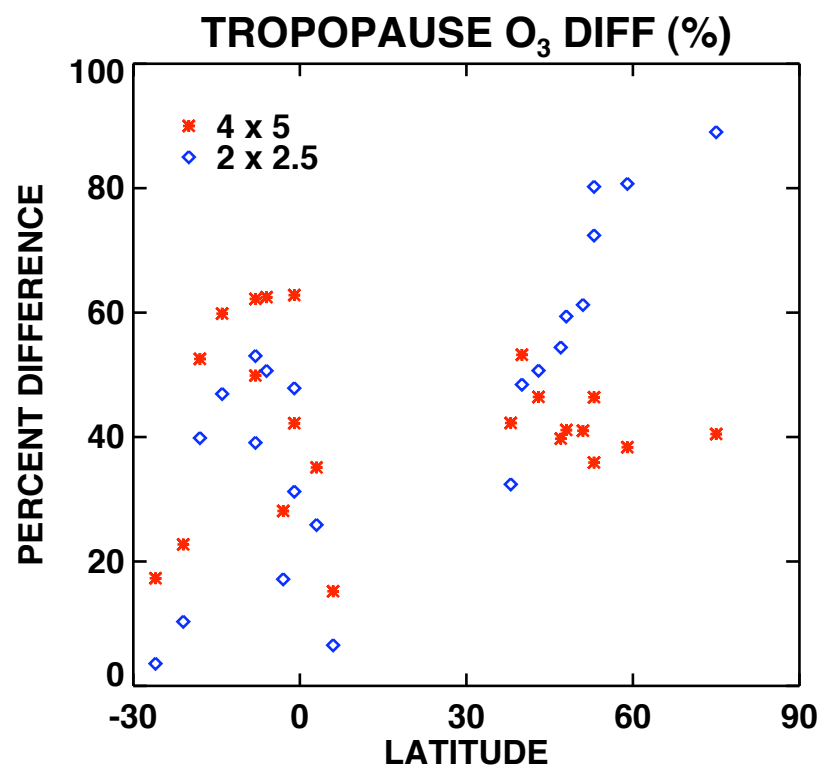

Fig. 7. Percent difference between modeled and observed annually averaged tropopause ozone for all stations, as a function of station latitude. Red asterisks show results from $4^{\circ} \times 5^{\circ}$ run, blue diamonds show results from $2^{\circ} \times 2.5^{\circ}$ run.

tropopause pressures (black crosses) are spread over the region within about one half of an e-fold of the monthly median tropopause pressure. Figure $9 \mathrm{~b}$ shows the same profiles in a RTT coordinate system, as well as the monthly mean profile averaged in RTT coordinates along with the plus and minus standard deviations. It is obvious that the profiles are more organized in Fig. 9b compared to Fig. 9a, especially near the tropopause, because a substantial fraction of the variability is related to daily changes in tropopause height. Fig. 9c compares the monthly average profiles and the standard deviations shown in Fig. 9a and b. It is important to note that to plot the RTT-average profile as a function of pressure in Fig. 9c, we have normalized the RTTaverage profile relative to the monthly median tropopause pressure. Figure $9 \mathrm{c}$ illustrates that pressure-averaging results in weaker cross-tropopause gradients and larger UT ozone mixing ratios than the RTT-averaged values near the tropopause. RTT-averaging also reduces the variability near the tropopause. Figure 9d shows the percent deviation of the pressure-averaged profile from the RTT-averaged profile. Differences peak in the UT, with pressure averaged values up to $40 \%$ higher than RTT-averaged results.

Figure 10 shows model ozone profiles at Edmonton. (Results from the $2^{\circ} \times 2.5^{\circ}$ run are shown, but there is little difference between the two resolutions.) Figure 10a shows that model tropopause pressure variablity is similar to observations (the standard deviation of the model tropopause pressure at Edmonton during January is $\sim 20 \%$ smaller than observations). As is observed, the RTT-averaged profiles shown
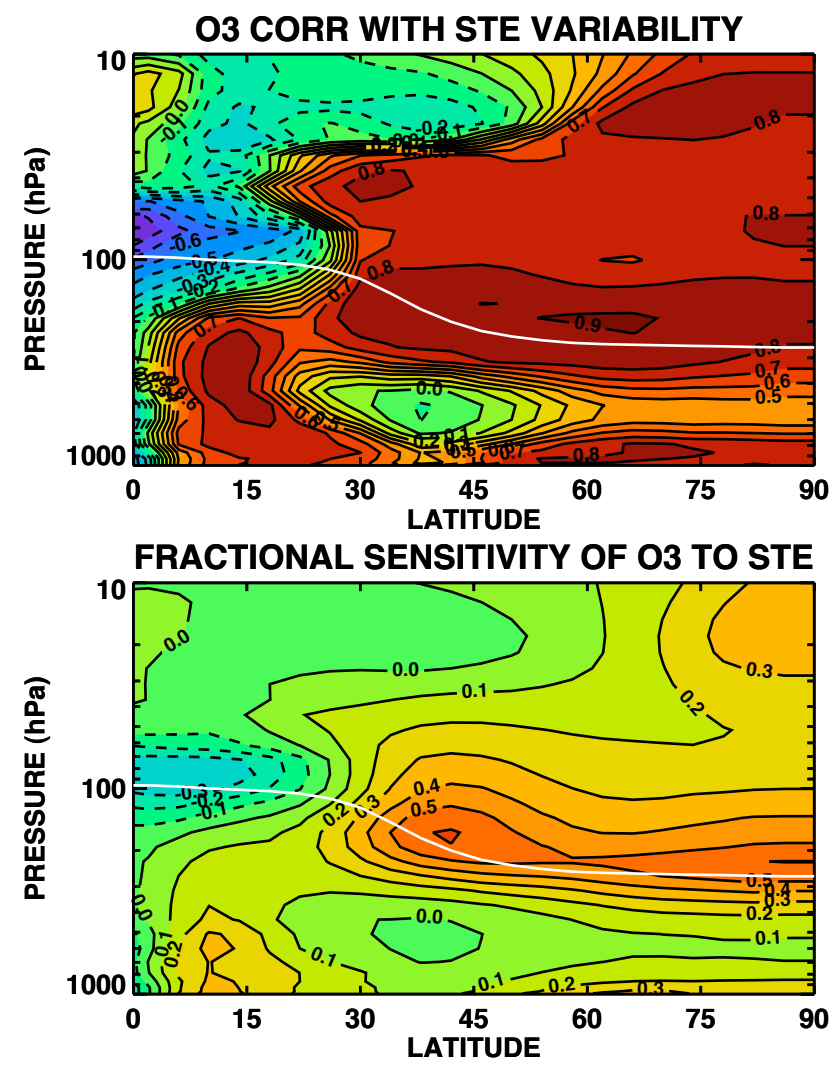

Fig. 8. Top panel: Distribution of linear correlation coefficients produced by regressing the monthly mean, zonal mean $\mathrm{O}_{3}$ at each latitude and pressure level in the $4^{\circ} \times 5^{\circ}$ run of the Combo model with the monthly mean cross-tropopause flux of $\mathrm{O}_{3}$ in the NH extratropics. Bottom panel: Fractional sensitivity of monthly mean, zonal mean $\mathrm{O}_{3}$ in the $4^{\circ} \times 5^{\circ}$ run to changes in the crosstropopause flux of $\mathrm{O}_{3}$ in the $\mathrm{NH}$ extratropics. Fractional sensitivity is defined as the fractional change in $\mathrm{O}_{3}$ mixing ratio per fractional change in the monthly mean cross-tropopause flux of $\mathrm{O}_{3}$, or $S=\mathrm{m} \times<F_{\mathrm{NH}}>/<\mathrm{O}_{3}>$, where $m$ is the slope of the linear regression, $<\mathrm{O}_{3}>$ is the mean monthly mean, zonal mean $\mathrm{O}_{3}$ over the 5year model integration at some latitude and pressure, and $\left\langle F_{\mathrm{NH}}\right\rangle$ is the 5-year mean $\mathrm{NH} \mathrm{O}_{3}$ flux.

in Fig. 10b are more organized than in Fig. 10a. Unlike the observations, Fig. 10c shows similar but smaller differences between pressure averaging and RTT-averaging, both in the change in upper tropospheric ozone values and profile variability. Figure 10d shows that the percent deviation of the pressure-averaged profile from the RTT-averaged profile is $\sim 8 \%$, smaller than the observed $\sim 40 \%$ difference shown in Fig. 9 d.

The results shown in Figs. 9d and 10d are typical at other locations and times of year. Model discrepancies between the two averaging techniques are generally small, while the differences between observed profiles averaged using these two techniques are much larger. Logan (1999a) showed that the vertical gradient in monthly averaged ozone profiles con- 

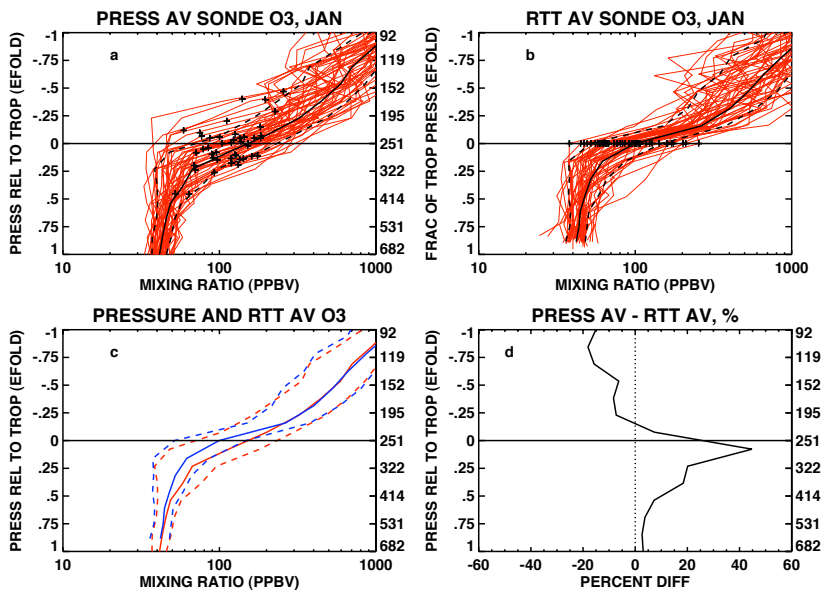

Fig. 9. (a) Daily ozonesonde profiles at Edmonton (red lines), plotted as function of pressure, for Januarys between 1985 and 2000. Left axis shows fraction of pressure efold from monthly median tropopause pressure. (The vertical axis is marked by the exponent $\mathrm{y}$, where $\mathrm{y}$ varies over the range $(-1,1)$, and the pressure is given by $\left.P_{\text {trop }} e^{y}\right)$. Right axis indicates pressure in $\mathrm{hPa}$. Black crosses indicate thermal tropopause pressures for each profile. Black solid line is monthly mean ozone profile averaged as function of pressure. Black dashed lines indicate \pm one standard deviation. (b) Red lines show ozonesonde profiles at Edmonton in January, plotted as fraction of efold of each profile's tropopause pressure. (The vertical axis is marked by the exponent $y$, which varies over the range $e^{1}$ to $e^{-1}$.) Black crosses indicating the tropopause now all lie at $y=0$. Black solid profile shows monthly average at constant fraction of tropopause pressure. Black dashed lines indicate \pm one standard deviation. (c) Comparison of monthly averaged profiles using pressure averaging (red lines) and relative-totropopause averaging (blue lines). Vertical axis is pressure. The relative-to-tropopause profile is plotted relative to the monthly median tropopause height. (d) Percent difference of pressure-averaged from RTT-averaged profiles.

structed from sondes is on the order of a factor of 2 steeper when averaged relative to the tropopause. Here, we see that the model does not correctly reproduce the atmosphere in this regard. As a result, good agreement between modeled and observed pressure-averaged results does not imply good correspondence between modeled and observed crosstropopause $\mathrm{O}_{3}$ profiles. Comparing RTT averages should provide a more accurate picture of the discrepancies between the model and observations.

We suggest an explanation of the model insensitivity to averaging technique, with the following heuristic example: Presume that the ozone change in the model between its characteristic stratospheric and tropospheric values is given by $\Delta \mathrm{O}_{3}$, and the characteristic vertical depth of the region over which the transition from stratospheric to tropospheric $\mathrm{O}_{3}$ values occurs is given by the distance $\Delta z_{\mathrm{NTR}}$. Then the ozone gradient across this region in a daily ozone profile is just $S=\Delta \mathrm{O}_{3} / \Delta z_{\mathrm{NTR}}$. We assume that this transition region
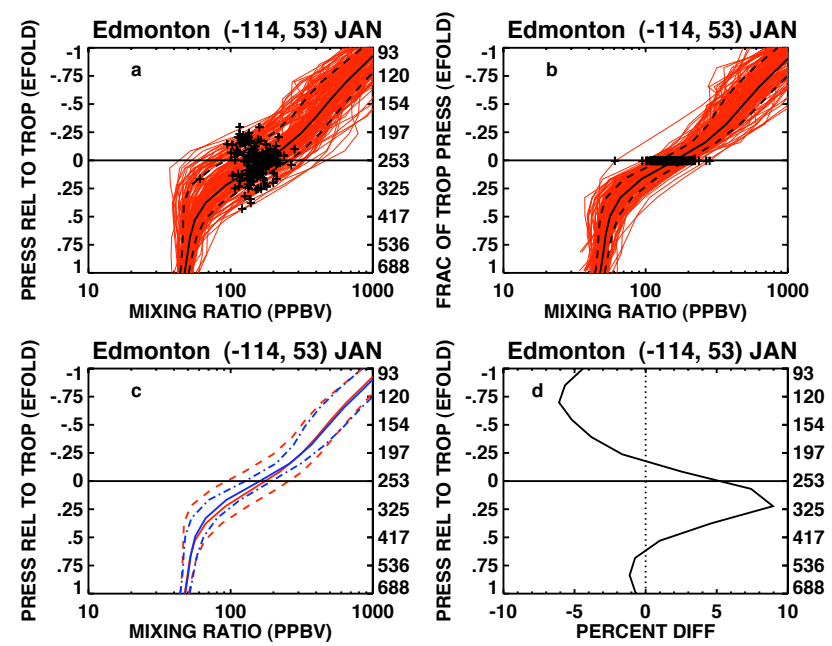

Fig. 10. Same as Fig. 9, except for the 155 daily GMI Combo model January profiles produced during the 1994-1998 model run.

will move up and down in altitude over the course of a month as the tropopause height varies. We label the characteristic variation in the height of the tropopause as $\Delta z_{\text {TROP }}$. Now, the RTT monthly average will by definition be insensitive to this movement, so we will just have: $\left\langle S>_{\mathrm{RTT}} \sim S\right.$. However, the tropopause height variability will smear the gradient in a pressure average, as each daily profile is shifted up or down by the movement of the tropopause. This results in a pressure-averaged mean slope of: $\left\langle S>\right.$ PRESS $\sim \Delta \mathrm{O}_{3} /$ $\left(\Delta z_{\mathrm{NTR}}+\Delta z_{\mathrm{TROP}}\right)=<S>\mathrm{RTT} \times \Delta z_{\mathrm{NTR}} /\left(\Delta z_{\mathrm{NTR}}+\Delta z_{\mathrm{TROP}}\right)$. This equation suggests that the larger the size of the transition region between the troposphere and stratosphere $\left(\Delta z_{\mathrm{NTR}}\right)$ relative to the monthly variability of the tropopause height $\left(\Delta z_{\mathrm{TROP}}\right)$, the smaller the difference between RTT and pressure averaging. Thus the weakness of the model daily profile vertical gradients shown in Fig. 10b can produce a smaller than observed sensitivity to the averaging technique. The equation also suggests that overly weak tropopause pressure variability could result in low sensitivity to averaging technique. However, the $\sim 20 \%$ weaker tropopause height variability seen in the model is not large enough to account for the much weaker model sensitivity to averaging technique compared to observations.

\subsection{Profile ozone comparisons}

Figure 11 shows $2^{\circ} \times 2.5^{\circ}$ run profile comparisons with observations of ozone mixing ratios from a pressure of half an efold below the observed monthly median tropopause pressure to half an efold above at Resolute, Hohenpeissenberg, and Ascension. Shown are model RTT-averaged monthly mean profiles, plotted relative to the model monthly median tropopause (red), and relative to the observed monthly median tropopause (green). Plotting relative to the observed monthly median tropopause allows comparison of modeled 

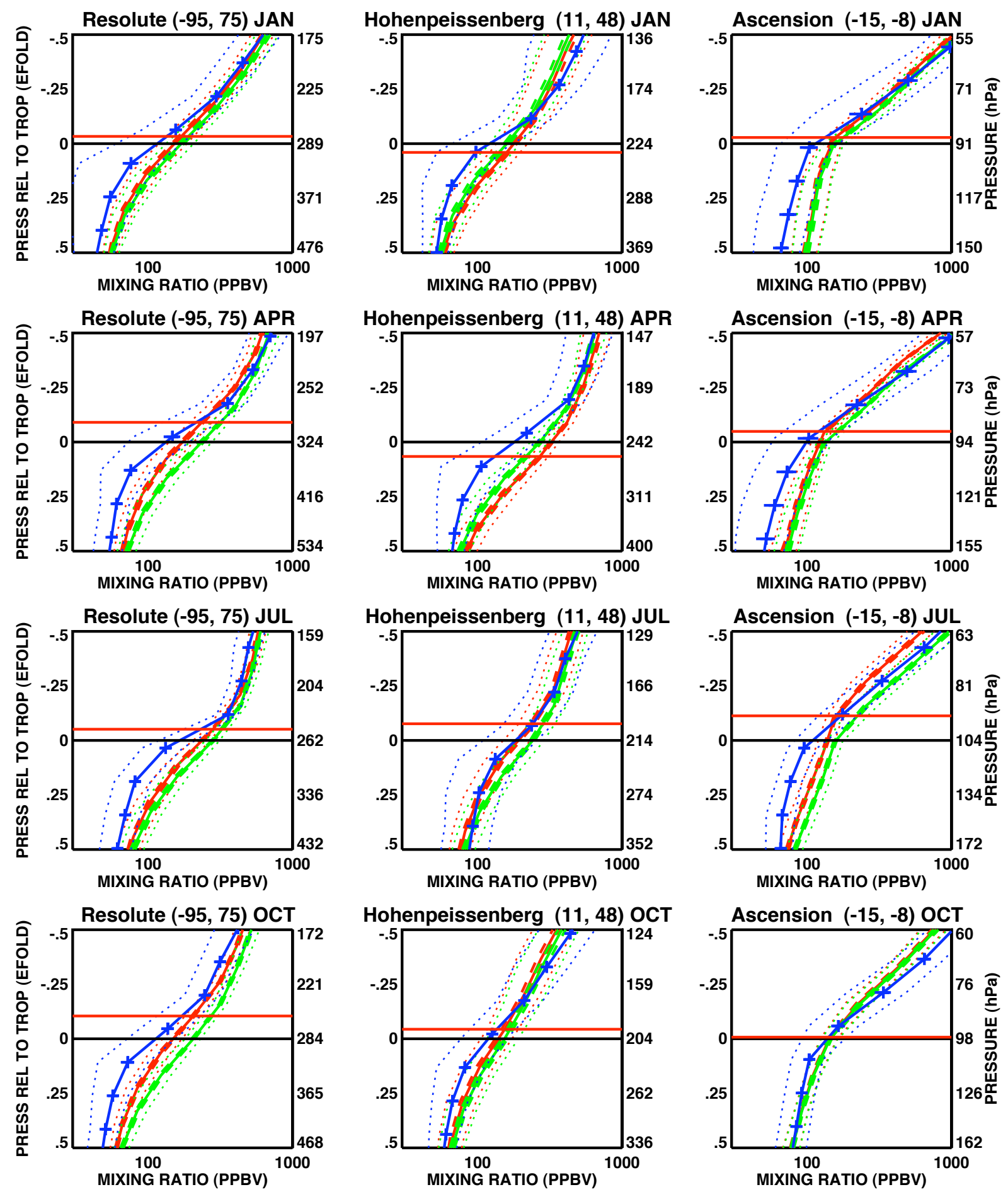

Fig. 11. Modeled and observed monthly average ozone profiles from the $2^{\circ} \times 2.5^{\circ}$ run at the stations of Resolute, Hohenpeissenberg, and Ascension for the months of January, April, July, and October. Blue line with crosses: observed RTT-averaged profile. Error bars indicate \pm 2 times standard error. Red line: Modeled RTT-averaged profile. Green line: Modeled RTT-averaged profile, plotted relative to the observed monthly median tropopause pressure, rather than relative to the model monthly median tropopause pressure. Dash-dot lines indicate \pm 2 times the standard error limits. Dotted lines indicate $\pm 1 \sigma$ standard deviations. Black and red horizontal lines indicate observed and model monthly median tropopause pressures, respectively. 
and measured RTT-averaged profiles at the same fraction of the tropopause pressure. (For instance, when $y=.25$, the observed profiles and the model profile represented by the green line are both a factor of $e^{0.25}$ higher than their respective tropopause pressures.) The figure also indicates standard errors and standard deviations for each of the profiles.

The RTT-averaged model profiles shown in Fig. 11 reproduce the characteristic shapes seen in the observations, but typically with weaker cross-tropopause gradients resulting in model high biases in the UT and sometimes low biases above the tropopause. Model profiles can reproduce the observations quite well, such as at Hohenpeissenberg in July, but often the upper tropopause high bias is substantial. It is interesting to note that normalizing the model profiles to the observed rather than modeled monthly median tropopause tends to increase the upper-tropopause high bias when the model tropopause lies above (at a lower pressure, which is typical) the observed monthly median tropopause, and decrease it when the model tropopause is found below the observed tropopause. This effect is distinct from the RTT-averaging process itself. While it is obvious that RTT averaging produces comparisons that better characterize model/measurement differences across the tropopause than pressure averaging, it is not clear if it is better to compare model and observed RTT-averaged profiles at the same pressure or at the same fraction of their respective tropopause pressures.

The standard error of the profiles shown in Fig. 11 are small and indicate that the mean profiles are known precisely enough that the differences between them are significant. The standard deviations of the profiles shown in Fig. 11 provide a comparison of observed and modeled variability of daily $\mathrm{O}_{3}$ profiles, separated from tropopause height variability due to RTT-averaging. Here we see that the model variability is weaker than observed. This is not surprising. Numerous observations show that atmospheric $\mathrm{O}_{3}$ has substantial variability at scales much smaller than the model grid, which will be reflected in ozonesondes but not in model daily profiles.

Because model values in the profiles shown in Fig. 11 correspond to layer averages, there is a potential source of error in the comparisons because the RTT climatology was generated by first interpolating daily ozonesondes to the RTT grid and then averaging the values. Thus, a value in an RTT profile does not represent a layer average if there is a nonlinear change in $\mathrm{O}_{3}$ between the bottom and top of the layer. We do not think this is a significant error. Because the effective vertical resolution of the sondes is about $300 \mathrm{~m}$ due to the time it takes to pump air through the sonde, there are typically only 3-4 points per layer - a small number with which to resolve any nonlinearity. We also tested the differences between interpolated values and layer averages by generating pseudo high-resolution profiles from the RTT climatology using cubic spline interpolation, and then constructing layer averages. This resulted in only $\sim 1-3 \%$ differences, showing that our method of constructing the RTT climatology is not a problem.

Figure 12 shows percent differences between the model and observed monthly mean profiles for the three stations shown in Fig. 11. (Note the larger vertical range in Fig. 12.) Here we show percent differences between model and observed pressure-averaged profiles (red), RTTaveraged profiles (blue), and RTT-averaged profiles normalized relative to the observed tropopause (green). Figure 12 shows better agreement between the modeled and observed pressure-averaged monthly mean ozone profiles than the RTT-averaged profiles, as expected. The pressure-averaged profiles show moderate model high-biases in the UT by $\sim 20$ $50 \%$. The bias in the lower stratosphere is smaller in magnitude and more variable between a high or low bias than in the UT. When RTT-averaging is used, biases between the model and the observations are larger; differences are typically about $\sim 50 \%$, but can exceed $100 \%$ (blue lines). When RTT-averaged profiles are compared at the same fractional value of the tropopause pressure (green lines), the model upper tropospheric high bias tends to be increased when the model tropopause pressure is lower than the observed tropopause pressure, as was also shown in Fig. 11.

Figure 13 is a bar chart summarizing April percent differences between the $2^{\circ} \times 2.5^{\circ}$ model run and observed ozone in the UT, at a pressure one quarter of an e-fold higher than the tropopause pressure. April is shown because the largest UT model discrepancies from observations occur in the March/April time period, while the smallest occur in June and July. Figure 13 illustrates that RTT-averaged (blue bars) and RTT-averaged profiles normalized to the observed tropopause (green bars) typically show substantially larger biases than the pressure-averaged profiles (red bars) at both the tropical and NH stations. The tropical stations of Paramaribo, Kuala Lumpur, San Cristobal, Nairobi, and Malindi exhibit particularly small biases. The mean NH pressureaveraged bias is $\sim 35 \%$, which approximately doubles with RTT-averaging. In the tropical mean, there are $\sim 20 \%$ high biases in the pressure-averaged case vs. a $\sim 30 \%$ difference for RTT-averaged profiles, resulting in a $\sim 50 \%$ difference between the averaging techniques.

Figure 14 shows the biases at all stations in the lower stratosphere, at a pressure one quarter of an e-fold below the observed monthly median tropopause pressure. Agreement in the lower stratosphere is generally substantially better than in the upper troposphere, with mean biases in the $\mathrm{NH}$ and the tropics $<20 \%$. Here, the RTT-averaged and normalized RTT-averaged biases are typically more negative than the biases between pressure-averaged profiles. This is the expected behavior of a profile with a weak cross-tropopause gradient - high biases in the UT, and low biases in the lower stratosphere. The five tropical stations with small UT high biases are shown here to have more substantial low biases in the lower stratosphere, indicating that the agreement of model cross-tropopause gradients with observations at these 

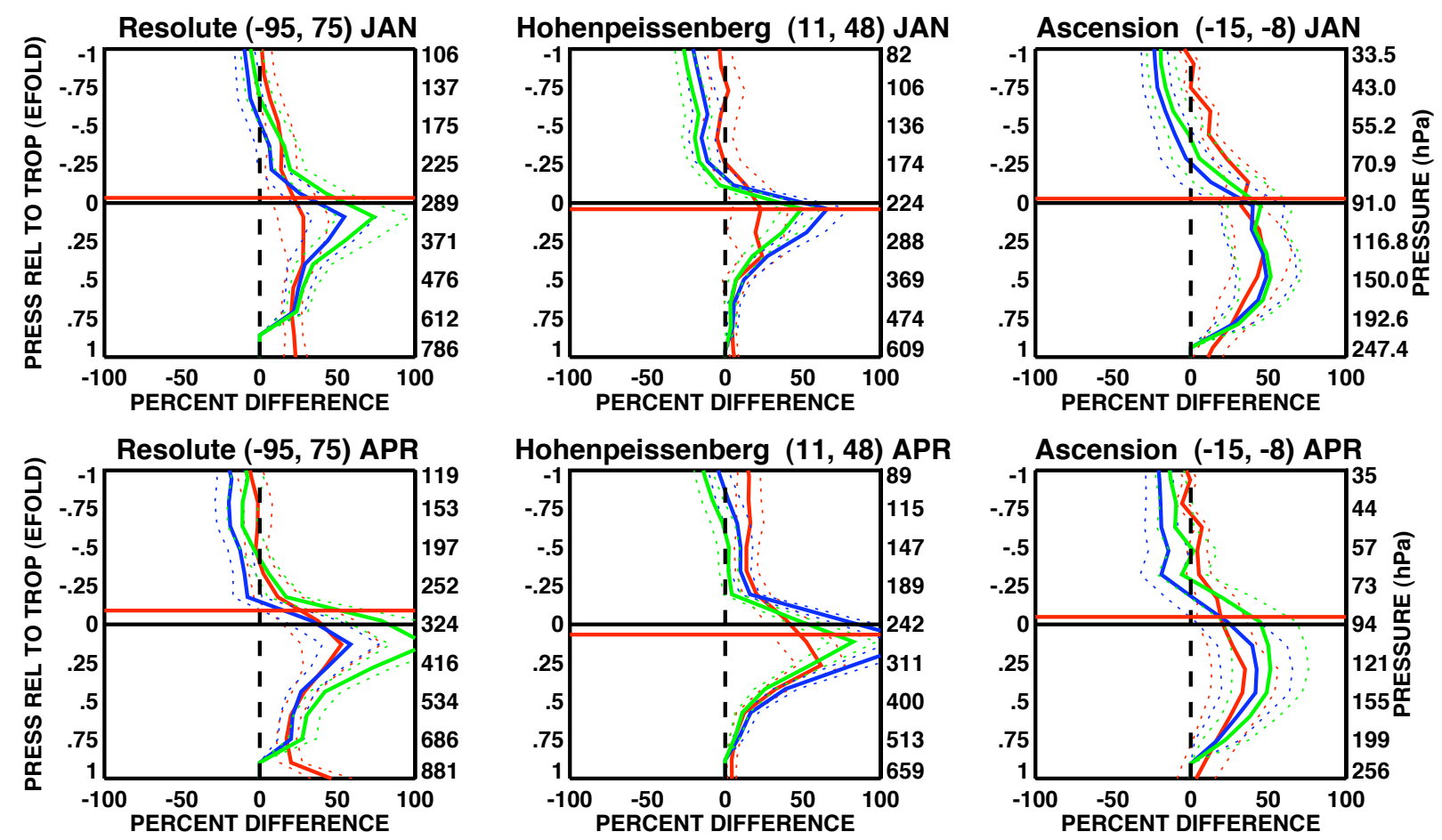

Hohenpeissenberg $(11,48)$ APR
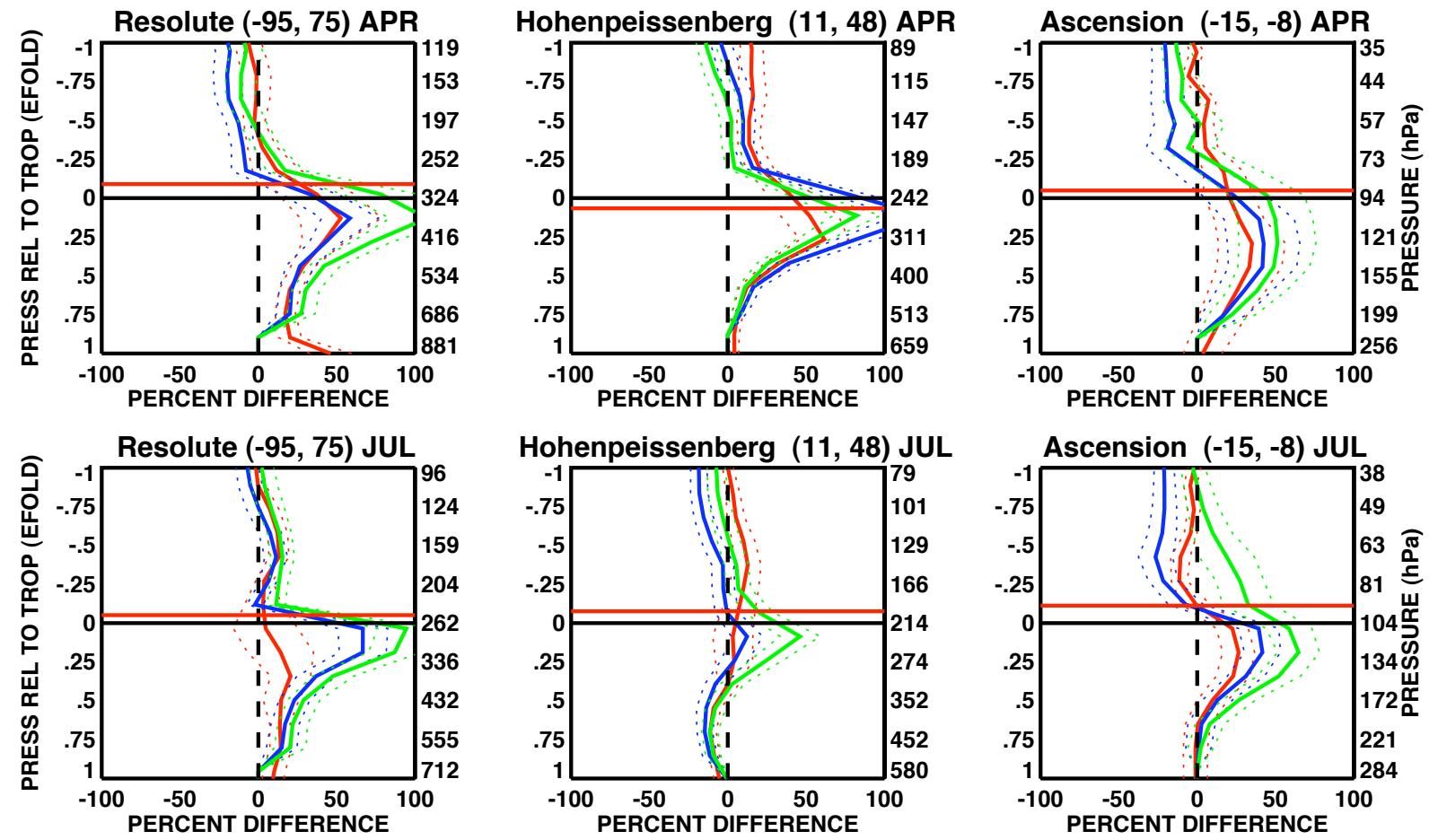

Hohenpeissenberg $(11,48) \mathrm{JUL}$
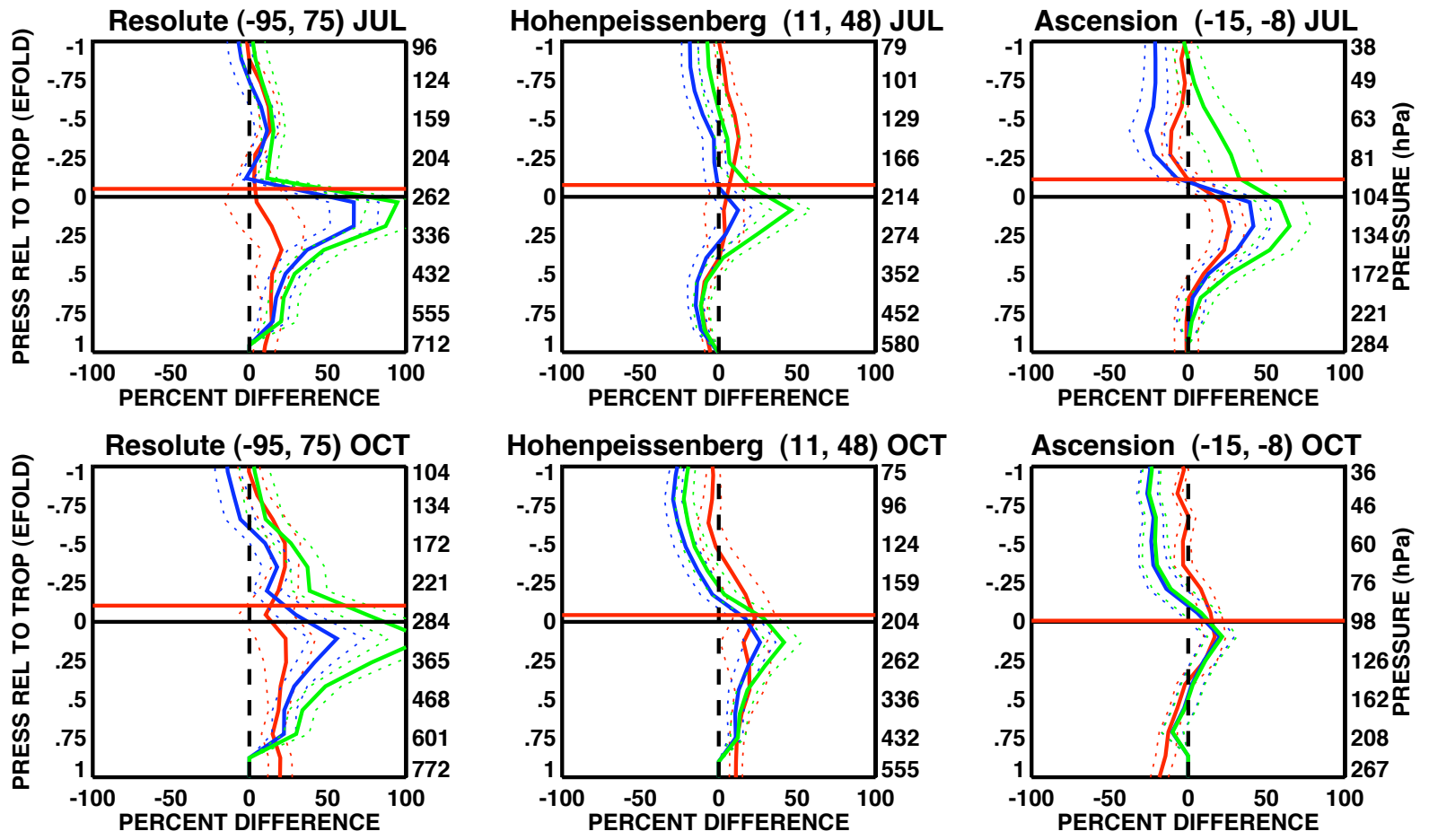

Fig. 12. Percent difference of modeled from observed monthly mean ozone profiles at Resolute, Hohenpeissenberg, and Ascension for the months of January, April, July, and October. Red lines: percent difference between pressure-averaged profiles. Blue lines: percent difference between RTT-averaged profiles. Green lines: percent difference between model and observed RTT profiles, with the model profile normalized to the observed tropopause pressure so that the difference is taken at the same relative fraction of the tropopause pressure. Dotted lines indicate \pm 2 times the standard error. 


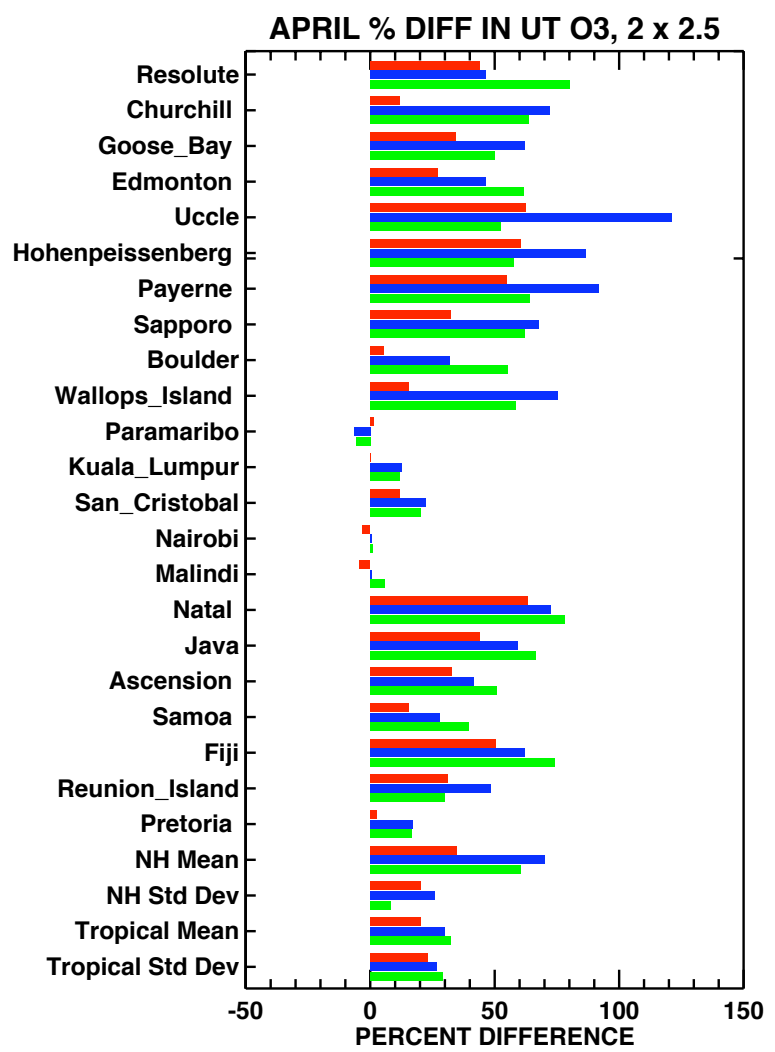

Fig. 13. Percent differences between modeled and observed ozone in the upper troposphere at observation locations, for the $2^{\circ} \times 2.5^{\circ}$ run. Red bar: Percent difference between observed and modeled pressure-averaged monthly mean ozone at a pressure that is one quarter of an efold higher than the observed monthly median tropoause pressure. Blue bar: Same as red bar, except for RTTaveraged monthly mean ozone. Green bar: Percent difference between observed and modeled RTT-averaged monthly mean ozone at one quarter of an efold above their respective tropopause pressures.

stations is similar to other stations.

Compared to the $4^{\circ} \times 5^{\circ}$ run, the $2^{\circ} \times 2.5^{\circ}$ run shows poorer agreement with observations at higher midlatitudes than the $4^{\circ} \times 5^{\circ}$ run, and similar agreement in the lower midlatitudes and tropics. Thus, increasing horizontal model resolution does not generally improve agreement between the ozonesonde observations and the model simulations in the NTR. The $2^{\circ} \times 2.5^{\circ}$ run high-bias increases at high-latitude stations suggests that the better-defined stratospheric subtropical and polar mixing barriers in the $2^{\circ} \times 2.5^{\circ}$ run may have increased STE at higher latitudes, resulting in larger ozone concentrations at higher midlatitudes in the NTR.

\subsection{Ozone annual cycle}

We now evaluate the model's ability to reproduce observed variations in phasing and amplitude of the annual cycle of $\mathrm{O}_{3}$ as a function of pressure. As noted by Logan (1999a, b)

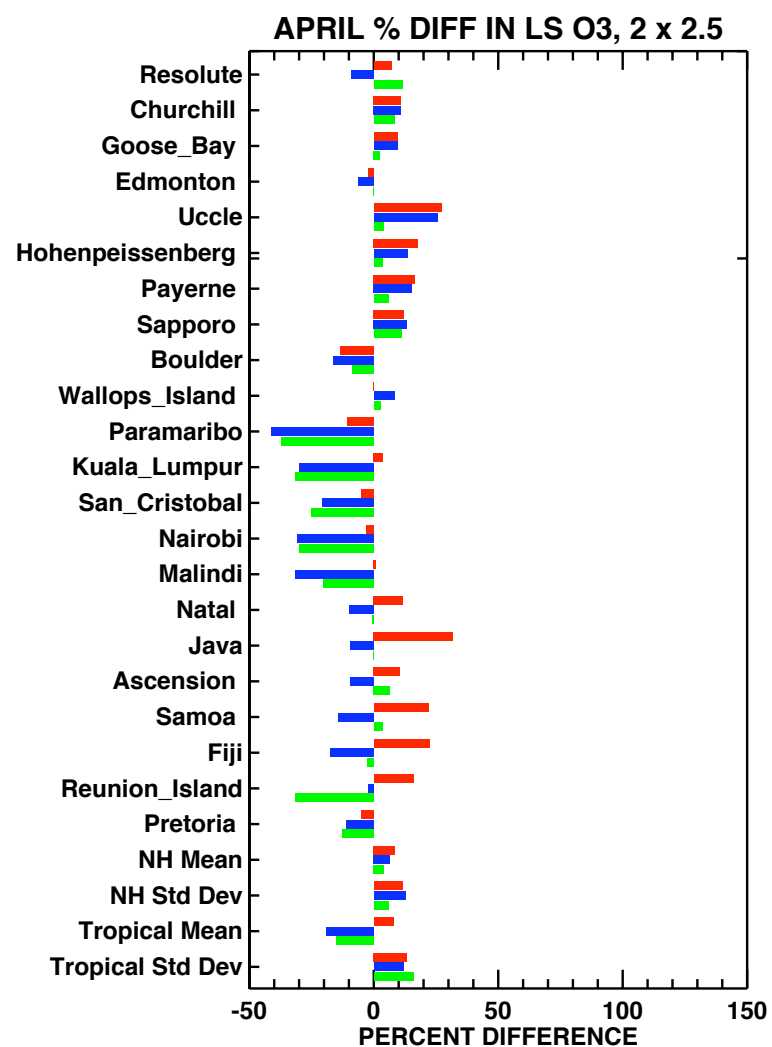

Fig. 14. Same as Fig. 13, except in the lower stratosphere at a pressure one quarter of an e-fold lower than the observed monthly median tropopause pressure.

and references therein, the peak in the observed midlatitude ozone annual cycle occurs in the late winter/early spring in the lower stratosophere and is the result of stratospheric dynamical processes. In the midlatitude mid-troposphere, the peak occurs in the late spring/early summer and is influenced by tropospheric chemical processes as well as stratospheric input. Vertical changes in phasing and amplitude therefore test the model coupling between the stratosphere and troposphere.

Figure 15 compares the percent deviation from the annual mean of the modeled and observed annual cycle of tropical ozone as a function of pressure. The figure shows the average over deep tropical stations within $10^{\circ}$ of the equator. While there is some variability amongst the tropical stations (Thompson et al., 2003b), an average over these stations is reasonably representative. The top left and right panels of Fig. 15 show pressure-averaged and RTT-averaged results, respectively. To construct the RTT-averaged annual cycles, the monthly RTT-averaged profiles were first interpolated to pressure coordinates using monthly median tropopause pressures. The bottom left and right panels show model pressureand RTT- averaged results for the $2^{\circ} \times 2.5^{\circ}$ run, respectively. Figure 15 shows that the strongest annual cycle is observed at 

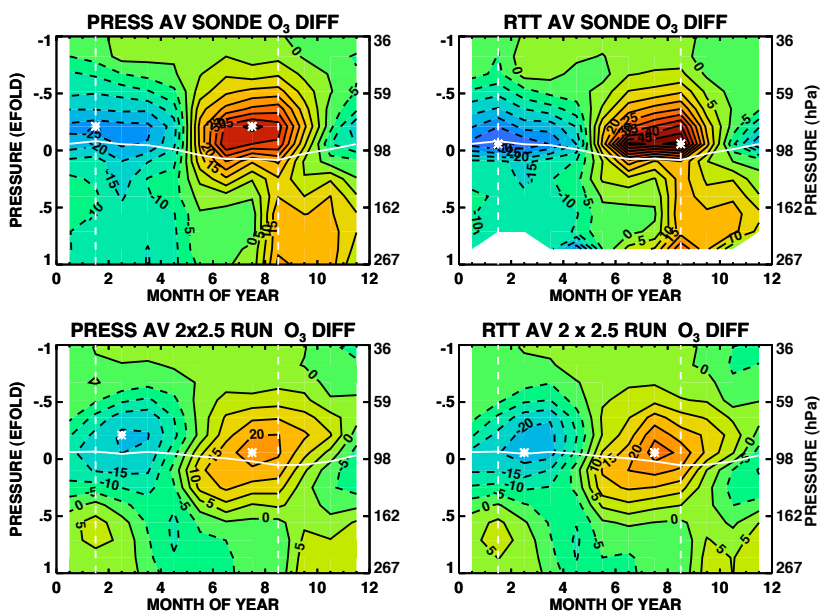

Fig. 15. Observed and modeled annual cycle of tropical ozone, expressed as percent deviation from annual mean ozone as function of pressure and time of year. Average includes stations within $10^{\circ}$ latitude of the equator. Top left panel: Annual cycle for observed pressure-averaged ozone profiles. Top right panel: annual cycle for observed RTT-averaged ozone profiles. Bottom left panel: annual cycle for model pressure-averaged ozone profiles from the $2^{\circ} \times 2.5^{\circ}$ run. Bottom right panel: annual cycle for model RTT-averaged ozone profiles from the $2^{\circ} \times 2.5^{\circ}$ run. White solid line in each panel indicates thermal tropopause pressure. Vertical dashed lines mark position of minimum and maximum tropopause pressure. Asterisks mark location of maximum and minimum values of annual cycle in ozone.

or just above the tropopause. In the observed RTT-averaged case (top right), the extrema have a greater magnitude, are temporally broader and vertically narrower compared to the pressure-averaged case.

The vertical variation of the amplitude and phasing of the model tropical annual cycle shown in Fig. 15 is qualitatively quite similar to the observations. However, the largest peak-to-peak amplitudes of the model annual cycles ( $\sim 43 \%$ and $\sim 51 \%$ for the pressure and RTT-averaged runs, respectively) just above the tropopause are weaker than the observed $\sim 70 \%$ and $\sim 88 \%$ variation in the pressure-averaged and RTT-averaged climatology, respectively.

Randel et al. (2007) present an analysis of the annual cycle in the vertical profile of tropical ozone, which argues that the fractional amplitude (i.e., amplitude divided by annual average) of the annual cycle in $\mathrm{O}_{3}$ mixing ratio is the product of the annual cycle amplitude in residual mean upwelling in the lower stratosphere and the fractional vertical gradient of annually averaged $\mathrm{O}_{3}$ in the tropics; the largest amplitude occurs where the $\mathrm{O}_{3}$ fractional vertical gradient is the largest. If this also holds for the model, its agreement with observations will depend on how well the model reproduces observed annual cycles in upwelling and annually averaged $\mathrm{O}_{3}$ fractional vertical gradients.

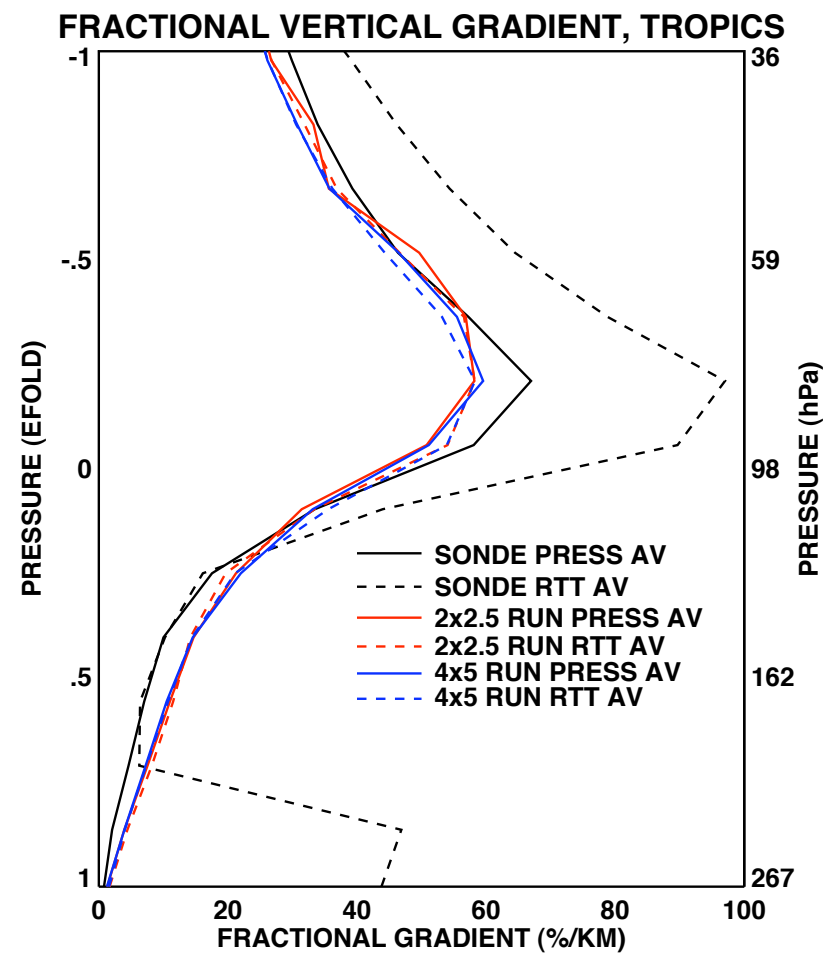

Fig. 16. Fractional vertical gradients of tropical, annually averaged $\mathrm{O}_{3}$ mixing ratio. Stations within $10^{\circ}$ of equator are included in averages. The fractional vertical gradient is defined as: $d / d z\left(\ln <\mathrm{O}_{3}>\right)$, where the brackets $<>$ denote an annual average, expressed in $\% / \mathrm{km}$.

Figure 16 compares the observed and modeled fractional vertical gradients in tropical, annually averaged $\mathrm{O}_{3}$ mixing ratio. The figure shows that the fractional vertical gradients are largest just above the tropopause for both the observations and the model runs. The observed fractional vertical gradients in the RTT-averaged case are substantially larger than the pressure-averaged case, with peak vertical gradients of $\sim 97 \% / \mathrm{km}$ and $\sim 67 \% / \mathrm{km}$, respectively. Neither the $4^{\circ} \times 5^{\circ}$ or the $2^{\circ} \times 2.5^{\circ}$ model runs show much difference between pressure - and RTT-averages. The model fractional vertical gradients peak at $\sim 58-59 \% \mathrm{~km}$ in both runs, $\sim 11 \%$ less than the observed pressure-averaged case. According to the Randel et al. (2007) analysis, this should result in an annual amplitude $\sim 11 \%$ lower than observed provided the modeled and observed vertical upwelling is equivalent. As shown in Fig. 15, the model pressure-averaged amplitude of $43 \%$ is $\sim 39 \%$ lower than observations. According to the Randel et al. (2007) analysis, this low bias indicates that in the model, the amplitude of the annual cycle in vertical upwelling at the tropopause level is $\sim 30 \%$ weaker than in the real atmosphere.

It is worth pointing out that the amplitude of the $\mathrm{O}_{3}$ annual cycle in the $4^{\circ} \times 5^{\circ}$ model run is larger than in the $2^{\circ} \times 2.5^{\circ}$ run, with largest peak-to-peak amplitudes of $49 \%$ and $59 \%$, 

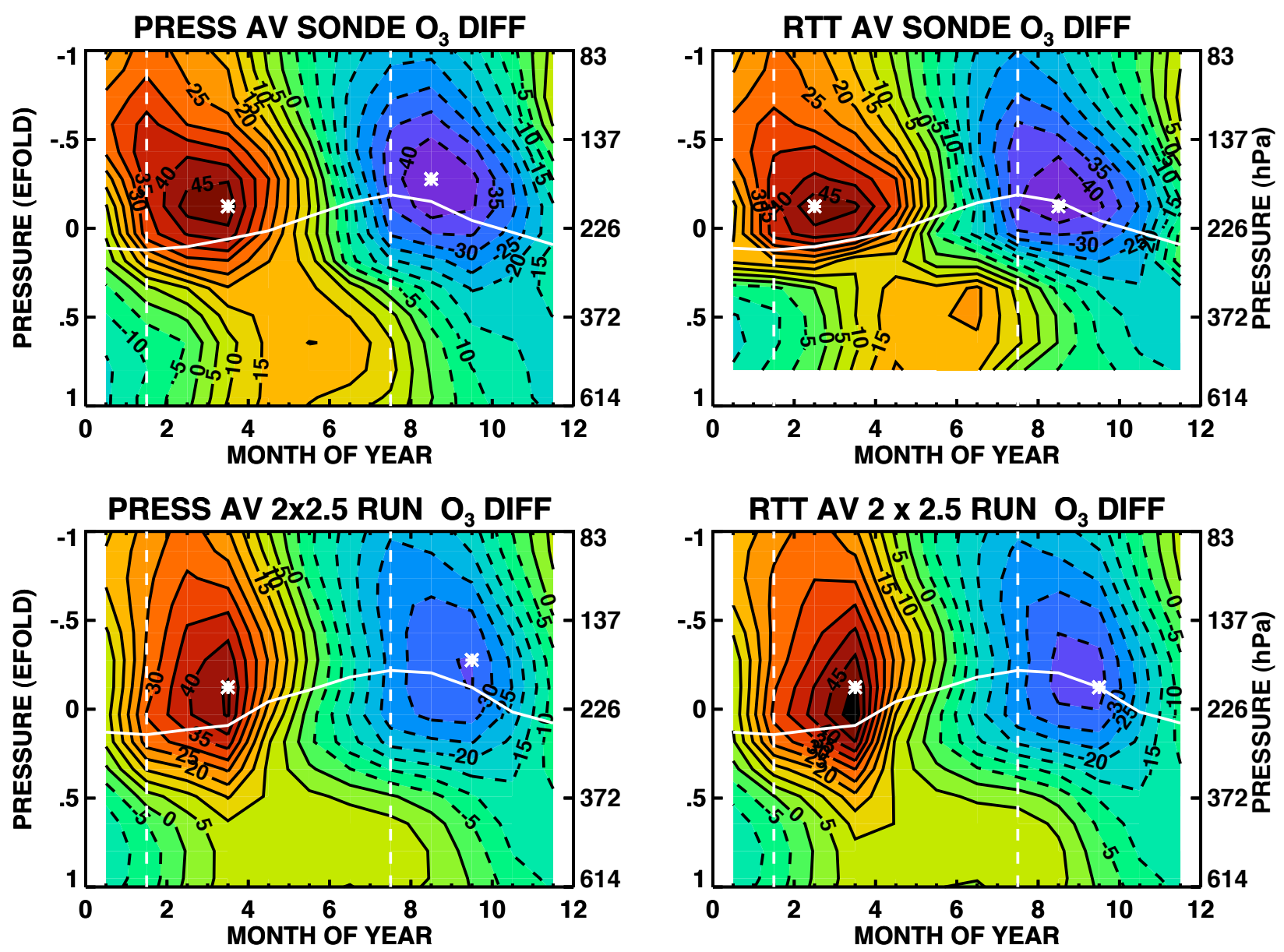

Fig. 17. Same as Fig. 15, except for midlatitude ozone stations (i.e., all stations with latitudes greater than $23^{\circ} \mathrm{N}$, except Tateno and Resolute).

in the pressure-averaged and RTT-averaged cases, respectively. The $49 \%$ amplitude is $\sim 30 \%$ lower than observations and suggests an upwelling $\sim 20 \%$ weaker than observations. However, resolution changes should not affect vertical upwelling, and Fig. 16 shows that the vertical $\mathrm{O}_{3}$ gradients are not resolution-dependent. The differences between the two resolutions appear to be due to the influence in the model of horizontal transport on the tropical seasonal cycle of $\mathrm{O}_{3}$, combined with the fact that the model peak amplitude of the seasonal cycle of $\mathrm{O}_{3}$ occurs at $\sim 15^{\circ} \mathrm{N}$. Though the peak amplitude is larger in the $2^{\circ} \times 2.5^{\circ}$ run, it is confined to a narrower range of latitudes. The confinement results in a lower amplitude annual cycle at the tropical stations included in Fig. 15.

Figure 15 shows that the annual maximum at pressures about half an e-fold below the tropopause occurs in October/November. The peak here is unlikely to be related to the annual cycle near the tropopause, because vertical ozone gradients are relatively low at these pressures, as indicated by Fig. 16. The signal is observable at most of the tropical sites, but is particularly strong at Fiji, Natal, and Reunion Island. The amplitude in the model is about half of the observed peak values. The model/measurement discrepancy is particularly large at Natal. It is well-known that biomass burning plays a strong role in tropical ozone during September-October (Thompson, 1996; Galanter et al., 2000), with lightning providing an important source of $\mathrm{NO}_{\mathrm{x}}$ at the beginning of the wet season (Martin et al., 2000). Although biomass burning emissions are included in the model, it may be that the Combo model underestimates its impact on tropical $\mathrm{O}_{3}$ concentrations in the mid-troposphere.

Figure 17 compares modeled and observed annual cycles at midlatitudes, following Fig. 15. (Stations not including Tateno north of $23^{\circ} \mathrm{N}$, except Resolute, which was excluded due to its high latitude.) The observed pressure-averaged and RTT-averaged plots shown in the top left and right panels are very similar. Both show the maximum in the annual cycle occurring in March or April, one to two months after the annual tropopause pressure minimum. The minimum of the annual cycle occurs in both cases one month after the occurrence 
of the annual tropopause maximum. Peak to peak amplitude of the annual cycle is $\sim 90 \%$. The RTT-average plot shows a closer association of the ozone annual cycle at the tropopause level with the annual cycle in tropopause height, as the peak occurs above the tropopause and the minimum occurs below the tropopause. Both panels show a phase shift in the timing of the peak above the tropopause to earlier in the year at higher altitudes. Below the tropopause the two panels both display the well-known shift in the phase of the peak from March/April to June/July in the mid-troposphere. However, in the RTT-average climatology shown in the middle panel, this shift is clearer.

The bottom left panel of Fig. 17 shows the pressureaveraged midlatitude annual cycle from the $2^{\circ} \times 2.5^{\circ}$ run. The $4^{\circ} \times 5^{\circ}$ run annual cycle is very similar. The model reproduces the observed changes in phase and amplitude of the annual cycle in ozone very well, with a peak-to-peak amplitude of $\sim 90 \%$ at the pressure level of the tropopause that is only slightly weaker than observations. There is less of a phase shift at higher pressures in the stratosphere, and the March/April peak amplitude shift to later in the year below the tropopause is less pronounced. Overall, however, the midlatitude agreement of the model with the observations shown in Fig. 17 is better than at tropical stations (Fig. 15) The RTT averaged annual cycle in shown in the lower right panel is very similar to the pressure-averaged result.

\section{Summary and conclusion}

The GMI Combo model fully resolves the important processes in the troposphere and stratosphere, uses a transport scheme shown to represent well vertical gradients in the NTR, and has been integrated using a modern GCMbased meteorological data set to minimize the possible effects of anomalous vertical diffusion that affects analyzed meteorological data. We have examined the ability of the Combo model to represent $\mathrm{O}_{3}$ distributions in the NTR by comparing it to two climatological $\mathrm{O}_{3}$ data sets constructed from ozonesondes. The ozonesonde observations have the high vertical resolution necessary for tropopause-level evaluations. They have been averaged both on pressure surfaces and relative to the tropopause, and include a relatively large amount of tropical data. We have tested the sensitivity of the results to horizontal resolution by considering both $4^{\circ} \times 5^{\circ}$ and $2^{\circ} \times 2.5^{\circ}$ versions of the model.

The overall stratospheric distribution of ozone produced by the GMI Combo model is in good agreement with satellite observations, suggesting the meteorological data represents the stratospheric residual circulation well. Despite this good agreement, Combo model annual mean ozone distributions are biased high at the $4^{\circ} \times 5^{\circ}$ model thermal tropopause, by $\sim 45 \%$ in both the SH tropics and NH midlatitudes. When model resolution is increased, the high bias increases to $\sim 61 \%$ in the $\mathrm{NH}$ midlatitudes and decreases to $\sim 31 \%$ in the tropics. Such an effect is expected due to a decrease in effective horizontal diffusivity in the higher resolution runs. We argue that problems with the GEOS-4 AGCM meteorology cannot explain the high biases because of the good agreement of our global ozone comparisons with observations, the unrealistically large changes in residual circulation we estimate are necessary to remove the bias, and the results of the Strahan et al. (2007) tests of the transport processes in the GEOS 4 AGCM. We thus infer that insufficient vertical resolution near the tropopause and/or too high vertical diffusivity are the likely causes. In a similar study, Pan et al. (2007) also find vertical resolution and diffusivity important to simulations of near-tropopause ozone distributions.

The tropopause $\mathrm{O}_{3}$ high biases in the Combo model would produce erroneous estimates of extratropical ozone STE if the method of calculation used tropopause ozone mixing ratios to calculate STE. The differential method for inferring STE presented in Olsen et al. (2004) is insensitive to tropopause ozone values, because it uses the balance between the changing amount of ozone in the lowermost stratosphere and ozone flux into the lowermost stratosphere to calcuate ozone crossing the tropopause. However, Olsen et al. (2004) do use tropopause ozone mixing ratios to calculate the relative amounts of diabatic and adiabatic STE. The use of the GMI Combo model in such a calculation would result in an overestimate of diabatic and an underestimate of adiabatic ozone STE.

The method of averaging observations and data to produce monthly mean profiles for comparison is an important consideration for UT comparisons. Comparison of pressureaveraged profiles suggest that model $\mathrm{O}_{3}$ agrees relatively well with observations. However, RTT-averaging reveals more significant discrepancies in the UT in both the SH tropics and $\mathrm{NH}$ midlatitudes. NH mean UT high $\mathrm{O}_{3}$ high biases during April in the model increase from $\sim 35 \% \pm 20 \%$ to $\sim 70 \% \pm 10 \%$ when profiles are RTT-averaged. The effect in the tropics is smaller, with $\sim 20 \% \pm 25 \%$ biases increasing to $\sim 30 \% \pm 28 \%$ with RTT averaging. This occurs because RTTaveraging of the ozonesondes better preserves the strong vertical gradients characterizing daily ozonesonde profiles than does pressure averaging, and thus provides a more revealing and representative comparison. The RTT-comparisons show that the model tends to have a broader transition region between the troposphere and the stratosphere than is seen in individual ozonesondes. Increasing the horizontal resolution of the model does not change this result much. Increasing the vertical resolution of the model (including the resolution of the meteorology) may produce stronger vertical ozone gradients in individual profiles and consequently better agreement with observations. Testing this idea requires running the model with higher vertical resolution. Unfortunately, there is currently no higher-resolution meteorological data set available with which the Combo model can be driven. Future plans for model development include this activity.

Observed and modeled RTT-averaged profiles can be com- 
pared either in a pressure coordinate system by normalizing to observed and model median tropopause pressures, or in a tropopause-relative coordinate system. We found that when modeled and observed tropopause heights differ substantially, the two methods can produce quite different results that are unrelated to the averaging process itself. It is important to be aware of these differences in order to fully understand what the model/measurement comparisons reveal.

In the lower stratosphere, modeled and observed $\mathrm{O}_{3}$ concentrations agree very well regardless of averaging technique. NH mean lower stratospheric biases are $\sim 10 \% \pm 10 \%$, for both pressure and RTT-averaged cases. In the tropics, the mean biases are $\sim 10 \% \pm 10 \%$ for pressure averaging, or $\sim-20 \% \pm 10 \%$ for RTT-averaged results. Strahan et al. (2007) compared Combo model ozone distributions to Aura MLS observations in the tropics and extratropics at potential temperatures between $350-400 \mathrm{~K}$, which are generally above the tropopause level. They also found very good agreement with MLS ozone during all seasons in the extratropics. This is consistent with our results that the model high bias tends to occur at and below the tropopause level. Strahan et al. (2007) also found the model to be low-biased relative to version 1.5 Aura MLS observations in the tropics at $350 \mathrm{~K}$, but found that may be due to MLS high-biases in the tropics at $215 \mathrm{hPa}$. Since we find mean model $20-30 \%$ high biases in the tropical UT compared to sonde observations, with the bias at some tropical stations reaching $~ 70 \%$, it appears that Aura MLS version 1.5 ozone in the tropical UT is high-biased with respect to the sonde observations.

The GMI Combo model captures the phasing but underestimates the amplitude of the observed relative annual cycle of ozone and its variation with altitude in the SH tropical NTR. Following the methodology of Randel et al. (2007), the underestimate of the amplitude appears to be too large to be explained by slightly weaker than observed vertical gradients in annually averaged $\mathrm{O}_{3}$, and suggests that the annual amplitude of mean residual upwelling at the tropopause level in the model is $\sim 30 \%$ less than in the real atmosphere. The model reproduces well the observed relative annual cycle of ozone and its variation with altitude at the $\mathrm{NH}$ midlatitude stations. However, the model does not have as rapid a shift from a springtime peak at the tropopause level to a summer peak in the mid-troposphere. Increases in horizontal resolution from $4^{\circ} \times 5^{\circ}$ to $2^{\circ} \times 2.5^{\circ}$ do not change this result, suggesting increases in vertical resolution may be necessary to resolve this problem.

Acknowledgements. We would like to thank S. Strahan and B. Duncan (Goddard Earth Sciences and Technology Center) and W. Randel (National Center for Atmospheric Research) for helpful discussions. We thank the GMI core modeling team as well as other members of the GMI science team for their efforts that have facilitated the research described in this paper. We would also like to thank I. Megretskaia (Harvard University) for her work producing the sonde-based climatologies utilized in this paper. We are grateful for support of the NASA Modeling, Analysis, and
Prediction (MAP) program. (D. Anderson, program manager), including grant NNG06GB93G to Harvard University.

Edited by: M. Dameris

\section{References}

Bey, I., Jacob, D. J., Yantosca, R. M., Logan, J. A., Field, B. D., Fiore, A. M., Li, Q., Liu, H., Mickley, L. J., and Schultz, M. G.: Global modeling of tropospheric chemistry with assimilated meteorology: Model description and evaluation, J. Geophys. Res., 106, 23 073-23 095, 2001.

Bloom, S., da Silva, A., Dee, D., Bosilovich, M., Chern, J. D., Pawson, S., Schubert, S., Sienkiewicz, M., Stajner, I., Tan, W. W., and Wu, M. L.: Technical Report Series on Global Modeling and Data Assimilation, Vol. 26: Documentation and validation of the Goddard Earth Observing System (GEOS) data assimilation system - Version 4, NASA/TM - 2005 - 104606, Vol. 26, 2005.

Chin, M., Ginoux, P., Kinne, S., Torres, O., Holben, B. N., Duncan, B. N., Martin, R. V., Logan, J.A., Higurashi, A., and Nakajima, T.: Tropospheric aerosol optical thickness from the GOCART model and comparisons with satellite and sunphotometer measurements, J. Atmos. Sci., 59, 461-483, 2002.

Chipperfield, M. P.: New version of the TOMCAT/SLIMCAT offline chemical transport model: Intercomparison of stratospheric tracer experiments, Q. J. R. Meteorol. Soc., 132, 1179-2003, 2006.

Considine, D. B., Douglass, A. R., Connell, P. S., Kinnison, D. E., and Rotman, D. A.: A polar stratospheric cloud parameterization for the global modeling initiative three-dimensional model and its response to stratospheric aircraft, J. Geophys. Res., 105, 3955-3973, 2000.

Considine, D. B., Bergmann, D. J., and Liu, H.: Sensitivity of Global Modeling Initiative chemistry and transport model simulations of radon-222 and lead-210 to input meteorological data, Atmos. Chem. Phys., 5, 3389-3406, 2005, http://www.atmos-chem-phys.net/5/3389/2005/.

Douglass, A. R. and Kawa, S. R.: Contrast between 1992 and 1997 high-latitude spring Halogen Occultation Experiment observations of lower stratospheric HCl, J. Geophys. Res., 104, 18739 $18754,1999$.

Douglass, A. R., Schoeberl, M. R., Rood, R. B., and Pawson, S.: Evaluation of transport in the lower tropical stratosphere in a global chemistry and transport model, J. Geophys. Res., 108, D94259, doi:10.1029/2002JD002696, 2003.

Douglass, A. R., Stolarski, R. S., Strahan, S. E., and Connell, P. S.: Radicals and reservoirs in the GMI chemistry and transport model: Comparison to measurements, J. Geophys. Res., 109, D16302, doi:10.1029/2004JD004632, 2004.

Duncan, B. N., Martin, R. V., Staudt, A. C., Yevich, R., and Logan, J. A.: Interannual and seasonal variability of biomass burning emissions constrained by satellite observations, J. Geophys. Res., 108(D2), 3100, doi:10.1029/2002JD002378, 2003.

Duncan, B. N., Strahan, S. E., Yoshida, Y., Steenrod, S. D., and Livesey, N.: Model study of the cross-tropopause transport of biomass burning pollution, Atmos. Chem. Phys., 7, 3713-3736, 2007 ,

http://www.atmos-chem-phys.net/7/3713/2007/. 
Galanter, M., Levy, H., and Carmichael, G. R.: Impacts of biomass burning on tropospheric CO, NOx, and O3, J. Geophys. Res., 105(D5), 6633-6653, 2000.

Gettelman, A., Kinnison, D. E., Dunkerton, T. J., and Brasseur, G. P.: Impact of monsoon circulations on the upper troposphere and lower stratosphere, J. Geophys. Res., 109, D22101, doi:10.1029/2004JD004878, 2004.

Hack, J. J.: Parameterization of moist convection in the National Center for Atmospheric Research community climate model (CCM2), J. Geophys. Res., 99, 5551-5568, 1994.

Holton, J. R., Haynes, P. H., McIntyre, M. E., Douglass, A. R., Rood, R. B., and Pfister, L.: Stratosphere-Troposphere Exchange, Rev. Geophys., 33, 403-439, 1995.

Horowitz, L. W., Liang, J., Gardner, G. M., and Jacob, D. J.: Export of reactive nitrogen from North America during summertime: Sensitivity to hydrocarbon chemistry, J. Geophys. Res., 103, 13 451-13 476, 1998.

Horowitz, L. W., Walters S., Mauzerall, D. L., et al.: A global simulation of tropospheric ozone and related tracers: Description and evaluation of MOZART, version 2, J. Geophys. Res., 108, 4784, doi:10.1029/2002JD002853, 2003.

Kinnison, D. E., Brasseur, G. P., Walters, S., et al.: Sensitivity of chemical tracers to meteorological parameters in the MOZART3 chemical transport model, J. Geophys. Res., 112, D20302, doi:10.1029/2006JD007879, 2007.

Lacis, A. A., Wuebbles, D. J., and Logan, J. A.: Radiative forcing of climate by changes in the vertical distribution of ozone, J. Geophys. Res., 95, 9971-9981, 1990.

Lin, S. J. and Rood, R. B.: Multidimensional flux-form semiLagrangian transport schemes, Mon. Weather Rev., 124(9), 2046-2070, 1996.

Logan, J. A.: An analysis of ozonesonde data for the troposphere: Recommendations for testing 3-D models and development of a gridded climatology for tropospheric ozone, J. Geophys. Res., 104, 16 115-16 149, 1999a.

Logan, J. A.: An analysis of ozonesonde data for the lower stratosphere: Recommendations for testing models, J. Geophys. Res., 104, 16 151-16 170, 1999.

Martin, R. V., Jacob, D. J., Logan, J. A., Ziemke, J. M., and Washington, R.: Detection of a lightning influence on tropical tropospheric ozone, Geophy. Res. Lett., 27, 1639-1642, 2000.

Müller, J.-F. and Brasseur, G.: Sources of upper tropospheric HOx: A three-dimensional study, J. Geophys. Res., 104, 1705-1715, 1999.

Olsen, M. A., Schoeberl, M. R., and Douglass, A. R.: Stratospheretroposphere exchange of mass and ozone, J. Geophys. Res., 109, D24114, doi:10.1029/2004JD005186, 2004.

Olsen, M. A., Schoeberl, M. R., and Nielsen, J. E.: Response of stratospheric circulation and stratosphere-troposphere exchange to changing sea surface temperatures, J. Geophys. Res., 112, D16104, doi:10.1029/2006JD008012, 2007.

Pan, L. L., Randel, W. J., Gary, B. L., Mahoney, B. L., and Hintsa, E. J.: Definitions and sharpness of the extratropical tropopause: A trace gas perspective, J. Geophys. Res., 109, D23103, doi:10.1029/2004JD004982, 2004.

Pan, L. L., Wei, J. C., Kinnison, D. E., Garcia, R. R., Wuebbles, D. J., and Brasseur, G. P.: A set of diagnostics for evaluating chemistry-climate models in the extratropical tropopause region, J. Geophys. Res., 112, D09316, doi:10:1029/2006JD007792,
2007.

Pickering, K. E., Wang, Y. S., Tao, W. K., Price, C., and Muller, J. F.: Vertical distributions of lightning NOx for use in regional and global chemical transport models, J. Geophys. Res., 103(D23), 31 203-31 216, 1998.

Price, C. and Rind, D.: A simple lightning parameterization for calculating global lightning distributions, J. Geophys. Res., 97(D9), 9919-9933, 1992.

Price, C., Penner, J., and Prather, M.: NOx from lightning 1. Global distribution based on lightning physics, J. Geophys. Res., 102(D5), 5929-5941, 1997.

Randel, W. J., Park, M., and Wu, F.: A large annual cycle in ozone above the tropical tropopause linked to the Brewer-Dobson Circulation, J. Atmos. Sci, 64, 4479-4488, 2007.

Rasch, P. J., Coleman, D. B., Mahowald, N., Williamson, D. L., Lin, S. J., Boville, B. A., and Hess, P.: Characteristics of atmospheric transport using three numerical formulations for atmosperic dynamics in a single GCM framework, J. Climate, 19, 2243-2266, 2006.

Rood, R. B., Douglass, A. R., Cerniglia, M. C., Sparling, L. C., and Nielsen, J. E.: Seasonal variability of middle-latitude ozone in the lowermost stratosphere derived from probability distribution functions, J. Geophys. Res., 105(D14), 17 793-17 805, 2000.

Rotman, D. A., Tannahill, J. R., Kinnison, D. E., et al.: Global Modeling Initiative assessment model: Model description, integration, and testing of the transport shell, J. Geophys. Res., 106, 1669-1691, 2001.

Rotman, D. A., Atherton, C. S., Bergmann, D. A., et al.: IMPACT, the LLNL 3-D global atmospheric chemical transport model for the combined troposphere and stratosphere: Model description and analysis of ozone and other trace gases, J. Geophys. Res., 109, D04303, doi:10.1029/2002JD003155, 2004.

Russell, J. M., Gordley, L. L., Park, J. H., Drayson, S. R., Hesketh, W. D., Cicerone, R. J., Tuck, A. F., Frederick, J. E., Harries, J. E., and Crutzen, P. J.: The Halogen Occultation Experiment, J. Geophys. Res., 98, 10777-10 797, 1993.

Schoeberl, M. R., Duncan, B. N., Douglass, A. R., Waters, J., Livesey, N., Read, W., and Filipiak, M.: The carbon monoxide tape recorder, Geophys. Res. Lett., 33, L12811, doi:10.1029/2006GL026178, 2006.

Stolarski, R. S. and Frith, S. M.: Search for evidence of trend slowdown in the long-term TOMS/SBUV total ozone data record: the importance of instrument drift uncertainty, Atmos. Chem. Phys., 6, 4057-4065, 2006,

http://www.atmos-chem-phys.net/6/4057/2006/.

Strahan, S. E. and Polansky, B. C.: Meteorological implementation issues in chemistry and transport models, Atmos. Chem. Phys., 6, 2895-2910, 2006, http://www.atmos-chem-phys.net/6/2895/2006/.

Strahan, S. E., Duncan, B. N, and Hoor, P.: Observationally derived transport diagnostics for the lowermost stratosphere and their application to the GMI chemistry and transport model, Atmos. Chem. Phys., 7, 2435-2445, 2007, http://www.atmos-chem-phys.net/7/2435/2007/.

Thompson, A. M., Pickering, K. E., McNamara, D. P., Schoeberl, M. R., Hudson, R. D., Kim, J. H., Browell, E. V., Kirchhoff, V. W. J. H., and Nganga, D.: Where did tropospheric ozone over southern Africa and the tropical Atlantic come from in October 1992? Insights from TOMS, GTE TRACE A, and SAFARI 1992, 
J. Geophys. Res., 101(D19), 24 251-24 278, 1996.

Thompson, A. M., Witte, J. C., McPeters, R. D., et al.: Southern Hemisphere Additional Ozonesondes (SHADOZ) 1998-2000 tropical ozone climatology - 1. Comparison with Total Ozone Mapping Spectrometer (TOMS) and groundbased measurements, J. Geophys. Res., 108(D2), 8238, doi:10.1029/2001JD000967, 2003a.

Thompson, A. M., Witte, J. C., Oltmans, S., et al.: Southern Hemisphere Additional Ozonesondes (SHADOZ) 19982000 tropical ozone climatology 2. Tropospheric variability and the zonal wave-one, J. Geophys. Res., 108(D2), 8241, doi:10.1029/2002JD002241, 2003b.

Wang, Y. H., Jacob, D. J., and Logan, J. A.: Global simulation of tropospheric O3-Nox-hydrocarbon chemistry 1. Model formulation, J. Geophys. Res., 103(D9), 10713-10725, 1998.

Wauben, W. M. F., Fortuin J. P., van Velthoven, F. J., and Kelder, H. M.: Comparison of modeled ozone distributions with sonde and satellite observations, J. Geophys. Res., 103, 3511-3530, 1998.
Wennberg, P. O., Hanisco, T. F., Jaegle, L., et al.: Hydrogen radicals, nitrogen radicals, and the production of $\mathrm{O} 3$ in the upper troposphere, Science, 279, 5347, 49-53, 1998.

WMO: Meteorology - A three-dimensional science, WMO Bull., 6, 134-138, 1957.

Zhang, G. J. and McFarlane, N. A.: Sensitivity of climate simulations to the parameterization of cumulus convection in the Canadian Climate Center general circulation model, Atmos. Ocean, 33, 407-446, 1995.

Ziemke, J. R., Chandra, S., Duncan, B. N., Froidevaux, L., Bhartia, P. K., Levelt, P. F., and Waters, J. W.: Tropospheric ozone determined from aura OMI and MLS: Evaluation of measurements and comparison with the Global Modeling Initiative's chemical transport model, J. Geophys. Res., 111, D19303, doi:10.1029/2006JD007089, 2006. 